\title{
The Impact of Changes in the Marital Status on Return-Migration of Family Migrants
}

\author{
Govert E. Bijwaard · Stijn van Doeselaar
}

Received: date / Accepted: date

\begin{abstract}
Many migrants have non-labour motives to migrate and they differ substantially from labour migrants in their migration behaviour. For family migrants the decision to return is highly influenced by changes in their marital status. Using administrative panel data on the entire population of recent family immigrants to The Netherlands, we estimate the effect of a divorce and remarriage on the hazard of leaving The Netherlands using a "timing-of-events" model. The model allows for correlated unobserved heterogeneity across the migration, the divorce- and remarriage processes. The family migrants are divided into five groups based on the Human Development Index (HDI) of their country of birth. We find that both divorce and remarriage increases return of family migrants from less developed countries. Remarriage of family migrants from developed countries makes them more prone to stay. Young migrants are influenced most by a divorce. The impact of the timing of a divorce and remarriage on return are quantified graphically.
\end{abstract}

Keywords temporary migration $\cdot$ timing of events method $\cdot$ marital status dynamics JEL Codes: J12, F22, C41

\section{Introduction}

International migration and the integration of migrants are among the most urgent social, economic and political issues in Europe today. In assessing the impact of migration and integration policies it is often overlooked that many migrants return to their home country or move on to a third country after a short period. The level of return migration has been high for both the US and in many European countries.

Govert E. Bijwaard

Netherlands Interdisciplinary Demographic Institute (NIDI) and IZA Bonn,

PO Box 11650, 2502 AR, The Hague, The Netherlands

Tel.: +31 703565 224, Fax: +31 70 3647187, E-mail: bijwaard@ nidi.nl

Stijn van Doeselaar

Hay Group 
(Jasso and Rosenzweig (1982)) report that between twenty and fifty percent of legal immigrants re-emigrated from US in the 1970s. (Bijwaard (2010)) reports return probabilities within five years between $25 \%$ and $50 \%$, depending on the migration motive, for migrants entering the Netherlands in 1995-2003. Similar numbers have been found for other Western European countries, see e.g. Edin et al (2000)) for Sweden, (Jensen and Pedersen (2007)) for Denmark and (Dustmann (1995)) for Germany. Despite the knowledge that many migrations are temporary the majority of the literature on migration still (implicitly) assumes migrations are permanent. When many migrations are temporary and the migrants that re-migrate are more successful than the migrants that remain in the country, then the recruitment or selection of migrants is only part of the issue. We need to know who re-migrates and why, and who stays and why.

The main focus in the economics literature on migration has been on the behaviour of labour migrants, see a.o. (Borjas (1999)), despite the fact that many migrants have non-labour related motives to migrate. In both Europe and the US family reunification and family formation are the cornerstone of immigration policies, e.g. $40 \%$ of recent migrants to the Netherlands are such family migrants. These migrants have less attachment to the host labour market. For example, (Jasso and Rosenzweig (1995)) and (Aydemir (2011)) have shown that skilled immigrants have relatively larger success on the labour market than family reunification immigrants. These family migrant groups also generally less mobile than labour migrants, (Bijwaard (2010)). Still only a few studies have looked at the behaviour of family migrants in detail. (Jasso and Rosenzweig (1995)) focus on family migrants to the US, (Aydemir (2011)) to Canada, (Miller (1999)) to Australia, (Rodriguez-Planas and Vegas (2011)) to Spain and (Bijwaard (2010)) to the Netherlands.

One issue ignored in the literature on family migration is the influence of marriage dissolution and remarriage on subsequent migration behaviour. When joining a spouse in a new country is the main reason to migrate we expect a large impact of a change in the marital status after arrival on possible return behaviour. Many factors that influence the divorce decision, like age and income, also influence the decision to return. Both these decisions are changing with the time spend in marriage and with the time spend in the host country. It is therefore more appropriate to view them as correlated processes instead of separate static decisions. The contribution of this paper is that we identify and quantify the impact of marital changes (both divorces and remarriages) on the return dynamics of family migrants. We also discuss how these effects vary by region of origin and by observed migrant characteristics. The failure of the empirical literature to address these issues arises from a combination of methodological challenges and severe limitations of the data usually encountered in migration analysis.

We address these novel questions using a unique administrative panel for the entire population of recent immigrants to the Netherlands covering the years 19992007. This Dutch immigrant register is based on the legal requirement for immigrants to register with the authorities upon arrival. A feature of our data is the administrative report in the immigrant register (consistent with the visa status at entry) of the immigration motive. This enables us to focus explicitly and exclusively on 100,392 family immigrants ( $40 \%$ of all recent (non Dutch) migrants). The data contain information 
on the (day-exact) timing of migration moves to and from the Netherlands and on the timing of marriage dissolutions and formations (while the migrant is registered in the Netherlands). Several other official registers are linked by Statistics Netherlands to this immigrant register, such as the social benefit and the income register (used by the tax authorities). The size of our data allows us to estimate our models separately for distinct immigrant groups defined in terms of the human development index of their country of birth.

While modern duration analysis (see e.g. (Van den Berg (2001)) for a survey) is widely applied in labour economics, the limitations of available data have prevented its widescale adoption in migration studies. One exception is, for instance, (Aydemir and Robinson (2008)) who estimate proportional hazard models for return migration on Canadian administrative data. We go beyond estimating such a model not only by allowing for unobserved heterogeneity in the migration process, but we also consider the divorce and remarriage processes jointly, for which unobservable heterogeneity is permitted to be correlated with that of the migration process. In particular, we estimate the effects of the timing of divorce and remarriage on the hazard to re-migrate using the "timing-of-events" method, (Abbring and van den Berg (2003)). At the same time, we control for the correlated effects that arise from the correlation between unobservables in the migration and divorce process (ignoring these, we show, would result in substantial endogeneity biases).

In our empirical analyses we find a large impact of both divorce and remarriage on the intensity to leave. Family migrants from less developed countries leave up to six times faster when they divorce. This translates into a forty percent-point higher return of divorced migrants ten years after arrival. Migrants from developed countries are, however, not affected by divorce. These migrants, who marry more often a native, are more prone to stay when they remarry, while family migrants from less developed countries, who marry more often a fellow migrant, are more prone to leave after remarriage. The impact of divorce on return is larger for migrants who arrived in the Netherlands at a younger age.

The outline of the paper is as follows. In Section 2 we briefly discuss the related literature on return- and on family migration. In Section 3 we present some background information regarding entry into the country and acquisition of a (permanent) residence of family migrants in the Netherlands. The econometric model is set out in detail in Section 4. In particular, we specify the divorce, the remarriage and the migration processes, and elucidate the role of unobservable heterogeneity. We also address the assumptions needed to allow for a causal interpretation of the estimated effect of marital changes on return. The data are described in Section 5, and the empirical results are presented in Section 6. Since the precise quantitative impacts on migration durations are complex, as they depend on both the timing and lengths of the marriage and divorce spells, Section 7 considers several quantification experiments. In Section 8 we present several sensitivity and robustness checks. The last section concludes. 


\section{Conceptual framework}

An important contribution to the theoretical explanations of return migration of immigrants is provided by (Borjas and Bratsberg (1996)). They attribute return migration to an optimal residential plan over the life cycle where immigrants return to source countries due to the realization of a savings goal or due to erroneous information about economic opportunities in the host country. Other theories attribute return migration to region-specific preferences ((Hill (1987)); (Dustmann and Weiss (2007))), higher purchasing power of host currency in source countries ((Dustmann and Weiss (2007))) or to greater returns for human capital acquired in the host country (Borjas and Bratsberg (1996)); (Dustmann and Weiss (2007)).

A problem with most of these explanations of return migration is that family migrants often have non-economic migration motives. This is illustrated by the fact that only $3 \%$ of the family migrants to the Netherlands are employed at entry ${ }^{1}$, and five years after entry this figure is still below $50 \%$. It seems that many family migrants mainly migrate to join their (future) spouse, at least initially. This implies that their personal situation in the host might be more important than their economic situation in explaining their return. Return migration of family migrants is therefore more susceptible to changes in marital status than return migration of labour migrants. Marriage dissolution may induce a family migrant to move. Of course, the behaviour of family migrants are also affected by (household) labour market and income changes. ${ }^{2}$

In the literature we have found some evidence of the prominent role family play in explaining return. (Gibson and McKenzie (2011)) find that family and lifestyle have a major impact on return decisions. Contrary to labour migrants, the majority of family migrants are female. It is therefore important to emphasize the gender difference in motivations for family migration. Migration of a household usually benefits the man's career. Women are less likely to be employed, have lower income following a migration as a couple, (Boyle et al (2001)). For a female spouse the cost (psychological difficulties, uncertainty) of moving may be higher and therefore, her preference for the source country might be higher, (Flowerdew and Al-Hamad (2004)). In such circumstances a woman looses her motivation to stay in the host after a divorce and this leads to return migration, (Nivalainen (2004)). Of course, women also benefit from better opportunities in the host, especially women from less developed countries. For these women marrying a Dutch, or another migrant who already has a permanent residence permit, may give them the opportunity to work in the host country. However, these women are generally less integrated and depend financially on their husband. In such a situation a divorce will trigger them to leave the host. This is less obvious for (female) family migrants from developed countries who are generally more integrated.

It is often found that migration leads to higher divorce rates, (Sandell (1977)) and (Boyle et al (2008)). The economic approach to marriage is usually based on the assumption that couples marry and remain together when the net gains from marriage are greater than those from being single, see (Becker (1974a); Becker (1974b);

\footnotetext{
1 In most cases this is also prohibited by law.

${ }^{2}$ For a thorough analysis of the labour market performance of (labour) migrants in the host country on their return decisions we refer to (Bijwaard et al (2013)).
} 
Becker (1991)). Even if the migration decision is motivated by maximization of family income, one of the partners may benefit more from the move than the other, (Mincer (1978)). This may change the gains from marriage for the 'tied-mover'. Moving is also a stressful life event and therefore increases the chances of divorce, (Flowerdew and Al-Hamad (2004)). Factors that influence the migration decision also influence the marriage dissolution decision. Divorce is more likely if the characteristics of the marriage imply relatively low gains from marriage or relatively low costs of divorce. The independence hypothesis suggests that women with higher wages have less to gain from marriage and therefore may have higher divorce rates, (Becker et al (1977)). Higher wages also imply the migrant has (used) better opportunities in the host and a divorce has less impact on the financial position of the woman. Children both discourages union dissolution and migration. Other demographic factors expected to influence separation and return migration rates include the duration of the union (duration in the country), religion and the age at union formation (entry into the country). Religion has a negative effect on union dissolution and as a proxy for cultural distance to the secular Dutch society it influences the ease to assimilate. Many factors that influence the decision to end a relation also influence the remarriage decision, although their impact may be reversed, (Becker et al (1977)).

An issue often neglected is that many relevant factors that influence both migration and marriage decisions are not available to the researcher. These behavioural aspects of migrants, such as personality traits and attitudes towards risk, are hard to measure (and absent in administrative data). However, ignoring such factors may lead to biased estimation results. Including random unobserved terms in the migration, marriage dissolution- and remarriage processes which are possibly intercorrelated are able to capture this missing information.

\section{Institutional background}

Partner immigration to the Netherlands is a heterogeneous phenomenon. In the 1970s and 1980s, the inflow was dominated by family reunification (mostly women and children reuniting with husbands/fathers who had migrated to the Netherlands as labour migrants in the 1960s and 70s) involving ethnically endogamous couples. In the Netherlands, this mostly involved first-generation Turks and Moroccans. Later on, in the 1980s and 1990s, family formation gained more prominence, as a significant percentage of first-generation and second-generation immigrants selected a partner from the family's country of origin, instead of reuniting with a partner they had lived with before that partner immigrated to the Netherlands. In the same period, the Netherlands witnessed an increase of ethnically exogamous relationships. It became not uncommon for the native Dutch to bring a non-EU partner to the Netherlands. This mostly involved men with a female partner from Eastern Europe, Southeast Asia or Latin America. Partner immigration for Dutch women, often involving African men, also began to represent a modest but notable segment of the flows.

A foreigner who wants to stay in the Netherlands for the purpose of family reunification has to apply for a temporary residence permit. The conditions attached to the granting of a temporary regular residence permit have been set out in general 
terms in the Aliens Act. Specific conditions for the purpose of family reunification can be found in the Aliens Decree and have been further elaborated in the Aliens Act Implementation Guidelines.

The first general condition for the granting of a regular temporary residence per$\mathrm{mit}$ is a valid provisional residence visa (mvv). Certain categories of foreign nationals are exempted from the provisional residence visa requirement. The most important category concerns foreign nationals who are exempted on the ground of their nationality. This provisional residence visa must be applied for in the country of origin or permanent residence. The conditions for the visa are the same as for the residence permit. Other general conditions for the granting of a regular residence permit are a valid passport, adequate financial resources and that the applicant must not present a danger to society. Recently, an additional requirement that a family migrant between 18 and 65 should pass a basic integration exam prior to his arrival in the Netherlands, was introduced. This requirement only applies to foreign nationals subject to the provisional residence visa requirement and was introduced after our observation period.

The minimum age requirement for family reunification in the Netherlands is 18 years (which was increased to 21 years in 2010) and for family formation 21 years. The sponsor can be someone with Dutch nationality, or with a foreign nationality with a residence permit. Family reunification can be applied for on the grounds of a registered or non-registered partnership between two people of a different or the same gender. The relationship should be permanent and monogamous and both partners should be unmarried, unless the marriage has not been annulled as a result of legal impediments. The spouses or partners are obliged to live together and lead a joint household. In case of a marriage or registered partnership this must be inscribed in the municipal administration.

The sponsor must have sufficient income. This income must be available for at least one year. The level of the income for family reunification must be $100 \%$ of the level of social assistance for a couple and the income level for family formation is the minimum wages (which was raised in 2004 to $120 \%$ of the minimum wage).

A residence permit for family reunification is in principle always granted for a temporary period of one year first. This temporary residence permit can be renewed if the conditions are still fulfilled. After three years the dependent spouse or partner of a Dutch national or a foreign national with a permanent residence status can apply for an independent temporary resident permit. Recently (beyond our observation window) the condition of passing an integration exam in the Netherlands for acquiring this independent residence status is required. Sufficient income is not a condition for this independent resident permit. After 5 years of legal stay someone can apply for a permanent residence status. Passing an integration exam (in case someone did not pass this exam for the independent residence status) and sufficient resources are conditions for this residence permit for indefinite duration. 


\section{Econometric Model}

We are interested in the effect of changes in the marital status of family migrants on their return behaviour. For both the migration and the marital status changes (divorce and remarriage) processes the timing of the transitions and the time between transitions is crucial. So the main outcome variables of interest are all durations. In a duration model the timing of a particular event is usually modeled in terms of the associated hazard. An advantage of a hazard model is that a hazard is invariant to right-censoring, i.e. the timing of the transition is only known to occur beyond the end of the observation window. Another reason to apply hazard models is that many relevant characteristics of the migrant, like for example income and employment status, may change over time. In hazard models it is straightforward to incorporate such time-varying variables. We follow common practice in duration analysis and use a proportional hazard $(\mathrm{PH})$ model, which expresses the hazard as the product of a baseline hazard, which is only a function of elapsed time and common to all individuals, and a covariate function which accelerates or decelerates exits. The baseline hazard captures the effect of the assimilation of migrants into the host country on the return hazard. The longer they stay, the more they adapt to the culture and the more they get detached from the source country. To accommodate unobserved heterogeneity (see e.g. (Van den Berg (2001)) for a discussion of the importance of this), the mixed proportional hazard model (MPH) extends the PH model by multiplying it by a time-invariant person-specific random effect.

The empirical challenge arises from the potential correlation between the divorce, remarriage- and migration processes which, if present and ignored, confound the effect of divorce and remarriage on return. We address this endogeneity issue by allowing for correlated unobservable heterogeneity. This provides us the opportunity to distinguish the direct impact of divorce from the correlation that can arise from the correlation between the unobserved heterogeneity terms (stemming from e.g. dynamic sorting). We also present the identification assumptions under which we have a causal interpretation of the effect of divorce and remarriage on the return intensity.

\subsection{Marriage process and the return hazard}

Generically, let $T$ denote the random time since first entry into the Netherlands that a particular event takes place. In particular, $T_{m}$ is the time the immigrant leaves the host country in order to return to the source country, $T_{d}$ is the time of divorce and $T_{r}$ of re-marriage. The length of a marriage in the host country is $\delta_{\text {mar }}(t)$, which is $T_{d}$ for a migrant who divorces, $T_{m}$ for a migrant who leaves while married, $T_{m}-T_{r}$ for a migrant who leaves while remarried, $T_{e}$ for a migrant who remains married and in the country till the end of the observation time, and $T_{e}-T_{r}$ for a migrant who remarries and remains in the country till the end of the observation. Because we ignore repeated divorces only the time of a divorce, $T_{d}$, gives a uncensored length of marriage. The length of divorce is denoted by $\delta_{d}(t)$, which is $T_{r}-T_{d}$ for a migrant who remarried after divorce. We observe a censored divorce length $T_{m}-T_{d}$ for a migrant who leaves 
the country while divorced or $T_{e}-T_{d}$ for a migrant who remains in the country till the end of the observation window after a divorce.

In Figure 1 we depict the marriage, divorce and migration duration of two arbitrary migrants. In accordance with our data definitions of Section 5, the migrant is married at the moment (s)he enters the country. Migrant 1 arrives after Migrant 2. The length of of Migrant 1's marriage spell (in the Netherlands) is $\delta_{\operatorname{mar}}\left(t_{d}\right)=t_{d}$. She remains in the country divorced until time $t_{m}$. It is unknown whether the migrant remains divorced after leaving the country. We do know that her divorce spell in the Netherlands has lasted for $\delta_{d}\left(t_{r}\right)=t_{m}-t_{d}$. Migrant 2 stays for a longer period in the country and experiences both a divorce and a remarriage. Her first marriage has length $\delta_{\text {mar }}\left(t_{d}\right)=t_{d}$. After a divorce of length $\delta_{d}\left(t_{r}\right)=t_{r}-t_{d}$ she remarries. This second marriage spell is terminated when she leaves the host country at time $t_{m}$, and has duration $\delta_{\text {mar }}\left(t_{d}\right)=t_{m}-t_{r}$. Note that the last marriage/divorce spell is always censored. Thus, migrant 1 only experiences an adverse shock (divorce) in her life that might induce her to leave and migrant 2 also experiences a positive shock (remarriage). We seek to determine the effect of such shocks, both in terms of their incidences and their durations, on the duration of the post divorce and post remarriage migration spell.

\section{Insert Figure 1 here}

We have three possible transitions: divorce, re-marriage and return migration. The conditional hazards till divorce and from divorce till re-marriage follow mixed proportional hazard models:

$$
\begin{gathered}
\theta_{d}\left(\delta_{\text {mar }}(t) \mid x_{d}(t), v_{d}\right)=v_{d} \lambda_{d}\left(\delta_{\text {mar }}(t)\right) \exp \left(x_{d}(t) \beta_{x}^{d}\right), \\
\theta_{r}\left(\delta_{d}(t) \mid x_{r}(t), v_{r}\right)=v_{r} \lambda_{r}\left(\delta_{r}(t)\right) \exp \left(x_{r}(t) \beta_{x}^{r}\right)
\end{gathered}
$$

with baseline hazard $\lambda_{k}$, unobserved time-invariant characteristics $v_{k}$, and observed time-varying characteristics $x_{k}$ where $k \in\{d, r\}$ denotes the marriage state transitions. In order to keep track of marriage events, we also define the associated time-varying indicators: the indicator $I_{d}(t)$ takes value one if the migrant is divorced at time $t$, and $I_{r}(t)$ indicates that the immigrant is re-married again after a period of divorce.

We allow $T_{m}, T_{d}$ and $T_{r}$ to be correlated through unobservable heterogeneity terms and through a possible direct effect of divorce and re-marriage on the migration hazard. The latter two are the effects we are interested in. We consider both the incidence of divorce and re-marriage as well as their duration, and allow the impact to vary systematically with observed characteristics. In our empirical implementation these three aspects (incidence, duration, heterogeneity) are considered progressively. Thus, the extended MPH model for the return hazard is

$$
\begin{aligned}
\theta_{m}\left(t \mid t_{d}, t_{r}, x_{m}(t), z(t), v_{m}\right)=v_{m} \lambda_{m}(t) \exp & \left(x_{m}(t) \beta_{x}^{m}+I_{d}(t)\left\{\gamma_{d}+\alpha_{d}\left(\delta_{d}\left(t_{d}\right)\right)+z_{d}(t) \phi_{d}\right\}\right. \\
& \left.+I_{r}(t)\left\{\gamma_{r}+\alpha_{r}\left(\delta_{r}(t)\right)+z_{r}(t) \phi_{r}\right\}\right) .
\end{aligned}
$$

The covariates $z$ in the (return) migration hazard are a subset of the time-varying characteristics of the migrants $x$. The duration impact, $\alpha_{k}$, are modelled by piecewise 
constant functions, so the effect of divorce and re-marriage are allowed to exhibit duration dependence.

The direct effect need to be distinguished from the correlated effect that arises from the correlation between the unobserved error terms $\left(v_{m}, v_{d}, v_{r}\right) \equiv v$ where $v$ is distributed according to some distribution function $G$.

\subsection{Endogeneity: Confounding unobservable heterogeneity}

We briefly discuss the important endogeneity issue. Due to dynamic sorting the distribution of $v_{d}$ among those who divorce at $t_{d}$ will differ from its population distribution. In particular, individuals with high $v_{d}$ will tend to divorce earlier than individuals with low $v_{d}$. If $v_{d}$ and $v_{m}$ are dependent, then the distribution $v_{m}$ for divorced migrants at a given time in the country will differ from the distribution of $v_{m}$ for migrants still married. Similarly, if $v_{m}$ and $v_{r}$ are dependent, then the distribution of $v_{m}$ among remarried migrants will differ from its population distribution. Therefore, one cannot infer the effect of divorce on the return-migration from a comparison of the realised durations of those who divorced at $t_{d}$ with the rest of the population, because one would then mix the direct effect of divorce on the duration with the difference in the distribution of $v_{m}$ between these migrants. In this case $I_{d}(t)$ and $I_{r}(t)$ will be endogenous, and $T_{d}, T_{r}$ and $T_{m}$ should be modelled jointly to account for dependence of the unobserved heterogeneity terms. Therefore, we allow $v_{d}, v_{r}$ and $v_{m}$ to be correlated.

We adopt a commonly applied two-factor loading model with two independent fundamental factors $W_{1}$ and $W_{2}$, both having a discrete distribution on $(-1,1)$ with $p_{j}=\operatorname{Pr}\left(W_{j}=1\right) .{ }^{3}$ This implies that the unobserved heterogeneity is defined as

$$
v_{k}=\exp \left(\alpha_{k 1} W_{1}+\alpha_{k 2} W_{2}\right)
$$

with $k=\{d, r, m\}$. Let $W=\left(W_{1}, W_{2}\right)^{\prime}, v=\left(v_{d}, v_{r}, v_{m}\right)^{\prime}$ and $A$ be the matrix of factor loadings with rows $A_{k}=\left(\alpha_{k 1}, \alpha_{k 2}\right)$. Note that this two-factor model is very general as it allows for positive and negative correlations among the unobserved heterogeneity terms. The variance-covariance matrix of the unobserved heterogeneity terms is given by $\operatorname{Var}(\ln (v))=A \operatorname{Var}(W) A^{\prime}{ }^{4}$. Using a two-point mass specification to model unobserved heterogeneity is common in duration analysis, and extending this to correlated processes by considering a factor-loading specification has also been pursued recently in Crépon et al (2012)) and (Osikominu (2013)).

\subsection{Causal interpretation in a Timing of Events Model}

The "timing-of-events" method of (Abbring and van den Berg (2003)) implies that the full effects of marriage dynamics on the return migration hazard, $\gamma_{d}+\alpha_{d}\left(t_{d}\right)+$ $z_{d}(t) \phi_{d}$ and $\gamma_{r}+\alpha_{r}\left(\delta_{r}(t)\right)+z_{r}(t) \phi_{r}$ in our framework, have a causal interpretation. This requires that divorce, re-marriage and return migration transitions are modelled

\footnotetext{
${ }^{3}$ We estimate $\tilde{p}_{j}$ with $p_{j}=\exp \left(\tilde{p}_{j}\right) /\left(1+\exp \left(\tilde{p}_{j}\right)\right)$ to assure that $0 \leq p_{j} \leq 1$.

${ }^{4}$ One additional restriction is needed for identification. We let $\alpha_{m 2}=0$.
} 
parametrically as mixed proportional hazards, as we have. Identification of the causal effect additionally requires that the so-called "no-anticipation"-assumption holds.

Denote by $t_{d}$ the time a divorce spell would start, and consider first the migration hazard at a time $t$ before the divorce. The (untestable) no-anticipation assumption requires that migrants do not anticipate the divorce by migrating before the anticipated event would occur. Note that leaving on the date the divorce occurs does not violate the identification assumption. Hence the migration hazard $\theta_{m}\left(t \mid t_{d}, t_{r}, x_{m}(t), v_{m}\right)$ is assumed to be affected only for $t>t_{d}$.

A possible threat to the validity of the no-anticipation assumption is that ending a relationship takes time and migrants may decide to leave before the marriage has officially terminated. For example, the migrant might be so unhappy in the current marriage that she prefers to return to her home country before separation. It is also possible that the legal procedure of separation has been initiated, but is yet not completed, nor registered before migration. In either case the existence of such a (latent) group of migrants would lead to an underestimate the causal effect of divorce on the migration hazard. We cannot deduce from our data whether many migrants leave in anticipation of a divorce. We are therefore cautious in using a casual interpretation of the effect of divorce on return migration. Still, the timing-of-events method corrects for possible endogeneity of the divorce process.

\subsection{Administrative Removal}

Before discussing the construction of the likelihood one data issue should be mentioned. Although in principle the exact date of emigration is known, some migrants do not officially inform the authorities that they are about to leave the host country. However, all citizens (immigrants and natives) are required to register with their municipalities (this is a pre-requisite for many social services, and for tax-benefit matters). It is thus clear that any migrant who has no entries in the tax-benefit register and does not appear in the register of another municipality must have left the country. Only the exact date of the departure is unknown. Such non-compliers are periodically identified and removed from the registers by the authorities in a step labelled "administrative removal".

We assume that the when a migrant is "administrative removed" and has "zero income at last observed time" implies that the migrant has left before the date the administrative removal is recorded, and after the last date of any observed change in the observed characteristics (e.g. labour market status, housing and marital status). Such limited information is equivalent to interval-censored data. For interval-censored data the exact timing of an event is unknown, but it is known that the duration ended in some period of time. If a migrant is administratively removed at duration $t_{a}$ and the last observed change for this migrant occurred at duration $t_{1}<t_{a}$, the contribution to the likelihood (for each of the three processes: marriage, divorce and return) of this migrant is the probability of survival (in marriage, divorce or in NL) till $t_{1}$ times the probability that the migrant experienced the event between $t_{1}$ and $t_{a}$. The latter probability is equal to one minus the survival probability from $t_{1}$ until $t_{a}$ given survival up to $t_{1}$. 
Let $a_{i}$ indicate whether the emigration of migrant $i$ was due to an administrative removal $\left(a_{i}=1\right)$. For an administratively removed migrant we introduce two different event dates: $t_{i}^{a}$ is the administrative removal date and $t_{i}^{1}<t_{i}^{a}$ is the date of the last recorded change in any of the characteristics of migrant $i$ before $t_{i}^{a}$.

\subsection{Likelihood Function}

We have data for $i=1, \ldots, n$ immigrants entering the Netherlands in our observation window. Let $M_{i}$ be the number of observed marriage spells of individual $i$. The indicators $\Delta_{i}^{\text {mar }}, \Delta_{i}^{d}$ and $\Delta_{i}^{m}$ signal whether the marriage, divorce or migration spell is uncensored. Thus, the likelihood contribution of migrant $i$ conditional on the unobserved heterogeneity $v=\left(v_{d}, v_{r}, v_{m}\right)$ is, in the light of the preceding discussions:

$$
\begin{aligned}
L_{i}(v)=\prod_{d=1}^{M_{i}}\left\{\left[\theta_{d}\left(\delta_{\text {mar }}\left(t_{d i}\right) \mid \cdot, v_{d}\right)^{\Delta_{i}^{\operatorname{mar}}} \exp \left(-\int_{0}^{\delta_{\text {mar }}\left(t_{d i}\right)} \theta_{d}\left(\tau \mid \cdot, v_{d}\right) d \tau\right)\right]^{\left(1-a_{d i}\right)}\right. \\
\left.\cdot\left[\exp \left(-\int_{0}^{\delta_{\text {mar }}\left(t_{d i}^{1}\right)} \theta_{d}\left(\tau \mid \cdot, v_{d}\right) d \tau\right)\right]^{a_{d i}}\right\}^{I_{\text {mar }}\left(t_{d i}^{-}\right)} \\
\times\left\{\left[\theta_{r}\left(\delta_{d}\left(t_{i}\right) \mid \cdot, v_{r}\right)^{\Delta_{i}^{d}} \exp \left(-\int_{0}^{\delta_{d}\left(t_{i}\right)} \theta_{r}\left(\tau \mid \cdot, v_{r}\right) d \tau\right)\right]^{\left(1-a_{i}\right)}\right. \\
\left.\cdot\left[\exp \left(-\int_{0}^{\delta_{d}\left(t_{i}^{1}\right)} \theta_{r}\left(\tau \mid \cdot, v_{r}\right) d \tau\right)\right]^{a_{i}}\right\}^{I_{d}\left(t_{r i}^{-}\right)} \\
\times\left[\theta_{m}\left(t_{i} \mid \cdot, v_{m}\right)^{\Delta_{i}^{m}} \exp \left(-\int_{0}^{t_{i}} \theta_{m}\left(\tau \mid \cdot, v_{m}\right) d \tau\right)\right]^{\left(1-a_{i}\right)} \\
\cdot\left[\exp \left(-\int_{0}^{t_{i}^{1}} \theta_{m}\left(\tau \mid \cdot, v_{m}\right) d \tau\right)-\exp \left(-\int_{0}^{t_{i}^{a}} \theta_{m}\left(\tau \mid \cdot, v_{m}\right) d \tau\right)\right]^{a_{i}}
\end{aligned}
$$

This likelihood naturally separates marriage (the first two lines), divorce and migration spells and for each spell allows for censoring and administrative removal. To simplify notation, we have suppressed the dependence on observed characteristics in the hazard rates. $I_{\text {mar }}\left(t_{i}^{-}\right)$indicates that the migrant is married just before $t_{i}$ and similarly $I_{d}\left(t_{i}^{-}\right)$indicates that the migrant is divorced. If the migrant was not administratively removed in her/his last marriage spell, $a_{d i}=0$ (first line), the contribution to the likelihood of a migrant with a marriage length of $\delta_{\text {mar }}\left(t_{d i}\right)$ months is the product of the hazard, $\theta_{d}$ (only if a divorce was observed, $\Delta_{i}^{\text {mar }}=1$ ) and the probability of remaining married for such a length, the survival function, and similarly for the contribution of the divorce and migration spell.

If the migrant was administratively removed at time $t_{d i}^{a}$ and the last observed change (other than marriage or migration) for this migrant occurred at duration $t_{d i}^{1}$ we only know that (s)he has left the country somewhere in the interval $\left(t_{d i}^{1}, t_{d i}^{a}\right)$ and therefore the likelihood contribution is the migration survival till $t_{d i}^{1}$ minus the survival till $t_{d i}^{a}$, see the sixth line of (5). If this administratively removed migrant is still 
married at $t_{d i}^{1}$ we only know that this marriage (in the Netherlands) lasted at least till $t_{d i}^{1}$ and the likelihood contribution of this is the (marriage) survival till $\delta_{\text {mar }}\left(t_{d i}^{1}\right)$, see the second line of (5). If this administratively removed migrant is divorced at $t_{d i}^{1}$ the likelihood contribution of this divorce spell is the survival till $\delta_{d}\left(t_{d i}^{1}\right)$, see the fourth line of (5). When no divorce occurs, the marriage duration is censored and remarriage is impossible then the likelihood contribution of remarriage becomes 1. Similarly the likelihood contribution of marriage is one while the migrant is divorced.

Integrating out the unobserved heterogeneity distribution we obtain the likelihood function

$$
L=\prod_{i=1}^{n} \iiint L_{i}(v) d G\left(v_{d}, v_{r}, v_{m}\right)
$$

where $G\left(v_{d}, v_{r}, v_{m}\right)$ is the joint distribution of the unobserved heterogeneity terms implied by the discussion of $v_{k}$ given by equation (4).

\section{Data on recent family migrants to the Netherlands}

We have administrative data on all legal immigration by non-Dutch citizens to the Netherlands, who entered during our observation window of 1999-2007. These migrants are registered in the Central Register Foreigners (Centraal Register Vreemdelingen, CRV), using information from the Immigration Police (Vreemdelingen Politie) and the Immigration and Naturalization Service (Immigratie en Naturalisatie Dienst, IND). It is mandatory for every immigrant to notify the local population register immediately after the arrival in the Netherlands if (s)he intends to stay in for at least two thirds of the forthcoming six months.

In addition to the date of entry and exit, the administration also records the migration motive of the individual. Either the motive is coded according to the visa status of the immigrant, or the immigrant reports the motive upon registration in the population register. Statistics Netherlands distinguishes between the following motives: labourmigrants, family migrants, student immigrants, asylum seekers (and refugees), and immigrants for other reasons. Note that EU-citizens are required to register in The Netherlands, just as natives are. See (Bijwaard (2010)) for an extensive descriptive analysis of the various migration motives. ${ }^{5}$ In particular, about $40 \%$ of all non-Dutch immigrants in the age group 18-64 are family migrants. Given the subject of the current paper, we focus exclusively on these family migrants. As it is possible that the official migration motive does not always match with the true intention of the migrants, we further require that the immigrant be married in the Netherlands within three months of their entry.

This immigration register is linked by Statistics Netherlands to the Municipal Register of Population (Gemeentelijke Basisadministratie, GBA) and to their Social Statistical Database (SSD). The GBA contains basic demographic characteristics of the migrants, such as age, gender and country of origin. From the SSD we have information (on a monthly basis) on the marital status, labour market position, income,

\footnotetext{
5 (Bijwaard et al (2013)) focus on labour migrants and the impact of labour market dynamics on their return.
} 
industry sector, housing and household situation. It is important to note that this information is only available for migrants during their stay in the Netherlands. When migrants leave any change in their marital or labour market status is unrecorded.

Although in principle the exact date of emigration is known, some migrants do not officially inform the authorities that they leave. The departure of these non-complying individuals is registered as an "administrative removal" after the authorities have assessed that the migrant has left the municipality without showing up in the files of another municipality in The Netherlands or as an emigrant. These administrative removals are included among emigration and they amount to around $25 \%$ of all emigrations. $90 \%$ of these administrative removed migrants have no observed income in the Netherlands the moment they are removed. We conjecture that the majority of these migrants have left the country shortly after they stopped receiving income (either earnings or benefits). For those who still have income until they are administratively removed we assume that they left at that exact date. We have explicitly addressed the issue of administrative removals in the formulation of the likelihood, see Section 4.4 and 4.5.

In total we use a large panel of 100,392 family migrants, together experiencing 21,316 return-migrations, 103,545 marriage spells (9,127 divorces). The size of the family migration population allows us to conduct separate analyses for distinct migrant groups. The two main source countries of family migrants Turkey and Morocco are treated separately. Further, we distinguish three migrant groups according to the human development index (HDI) of the produced by the United Nations Development Programme (UNDP) of their country of birth: developed countries (DC), HDI > 0.7, intermediate developed countries (IDC), HDI $0.6-0.7$ and less developed countries (LDC), HDI $<0.6$ (UNDP (2011)). These group boundaries are approximately equal to UNDP identifiers. More specific data information can be found in the appendix. In Section 8.2 we test how sensitive the results are to this grouping.

\subsection{Summary Statistics for Family Migrants}

In Table 1 we give some first insights in the migration and relationship dynamics of the family migrants. Note that the group of 'stayers' includes permanent migrants, and temporary migrants who have not yet returned. For all three groups the majority of family migrants are stayers, with migrants from developed countries showing higher mobility and migrants from Morocco the least. However, most of the migrants that return, do so within five years. Conditional on return migrants from less developed countries stay longer than the other migrants. These differences highlight already the importance of an analysis disaggregated by HDI. Figure 2 depicts the Kaplan Meier estimates of the return probabilities ( $=1-$ survival probabilities) by immigrant group. The return of family migrants from intermediate- and less-developed countries and from Turkey and Morocco looks very similar. Migrants from developed countries are much prone to leave (more than twice as much) than migrants from the other groups. Overall, both Table 1 and Figure 2 highlight the importance of the temporary nature of family migration. Across all immigrant groups, a substantial proportion leave the Netherlands eventually. 


\section{Insert Table 1 here}

\section{Insert Figure 2 here}

Turning to the relationship dynamics, Table 1 reveals that migrants from developed and less developed countries experience less marriage volatility. Migrants from developed countries have been married for a shorter period when they divorce. Figure 3 depicts the Kaplan-Meier estimates of the probability to remain married by immigrant group. These probabilities are slightly higher for the migrants from less developed countries and the lowest for migrants from intermediate developed countries.

Only a small portion of the migrants remarry $(0.4 \%$ to $1.8 \%)$, with migrants from less developed countries the least and migrants from Morocco the most. The survival rates in divorce till remarriage, depicted in Figure 4, show that migrants from less developed countries remain divorced longer and migrants from Morocco and Turkey remarry sooner.

\section{Insert Figure 3 here}

\section{Insert Figure 4 here}

In Table ?? we condition on divorced migrants who leave. In line with Table 1, migrants from developed countries are less often divorced when they leave (3\%) while migrants from Morocco are more often divorced at departure. Migrants from less developed countries have had a longer (preceding) marriage duration and divorce length when they leave divorced. Migrants form Turkey and Morocco who leave divorced were married relatively short. This all implies that marriage dynamics of these recent migrants is substantial and associated with return.

\section{Insert Table 2 here}

\section{Estimation results}

We consider three versions of our model given by equation (3) (together with (1) and (2)). Recall that the causal impact of divorce on return migration hazard is given by $\gamma_{d}+\alpha_{d}\left(\delta_{d}\left(t_{d}\right)\right)+z_{d}(t) \phi_{d}$ and of remarriage by $\gamma_{r}+\alpha_{r}\left(\delta_{r}\left(t_{r}\right)\right)+z_{r}(t) \phi_{r}$. In Model 1 the effect of divorce and remarriage are assumed constant across time and migrants and thus given by $\gamma_{d}$ and $\gamma_{r}$ (with $\alpha \equiv \phi \equiv 0$ ). In Model 2 the covariate effect is still forced to zero, but the effects of sojourn times are allowed to exhibit duration dependence. This is implemented non-parametrically by modelling the sequence $\{\alpha\}$ as piece-wise constant functions. In Model 3 we further allow the effect to be heterogeneous across migrants in terms of $z$ which measure demographics (gender and age) and income level.

Although of secondary interest, we first briefly discuss the effect of other covariates on the migration-, divorce- and remarriage processes (based on the results of model 3), before we turn to the discussion of the effect of marital changes on return migration. 


\subsection{Migration process}

The covariates included in the migration hazard refer to individual demographic, individual labour market characteristics, characteristics of the country of birth and the macro economic situation in the host country. We reckon that the demographic factors such as gender, age at entry, whether the migrant owns a house in the Netherlands and number of children, influence the decision to return. Individual labour market characteristics include the employment status and monthly income. Religion and distance to the Netherlands of the country of birth capture the remaining heterogeneity within the migrant groups. Religious beliefs are very likely to have an effect on relationship transitions. Not only the beliefs of the individuals, but also the social environment in both the source and the host country may have an impact on relationship decisions and therefore also, indirectly, on (re-)migration. However, the religious background of the migrant is not registered in our data-set. We have constructed two dummies for groups of countries in which more than 80 percent of the population practises the same religion, Muslim or Christian. Medium distance countries have their center between 2,000 and 5,000 km from the center of the Netherlands, and long distance countries are more than $5,000 \mathrm{~km}$. Macro- and business cycle factors are captured by the national unemployment rate (changing on a quarterly basis) and the national unemployment rate at the moment of entry. For developed countries a dummy for EU 15 countries is included, as migrants from those countries have freedom of movement. The baseline hazard has a piecewise constant form which changes with the year of stay. Note that many of these included covariates may change during the stay of the migrant: a.o. the number of children, the income indicators (no/low/high), the house-ownership indicator, employment status and, the national unemployment rate.

Table 3 reports the estimated coefficients of those control variables on the migration hazards $\left(\beta_{x}^{m}\right.$ in (3)). Male family migrants, who are a minority, are more inclined to return, especially males from Morocco. The Moroccan males often come from rural area's and therefor experience large cultural shocks when entering the Netherlands. Children in the family clearly inhibit return. This is in line with earlier findings of (Dustmann (2003)) and can be explained by the fear that migration might disrupt children's education. For labour migrants it is commonly found that both the younger and the older leave faster than those in their prime of their working age, see a.o. (Bijwaard (2010)). We find, consistent with (Bijwaard (2010)), that for family migrants the return hazard increases with age. A reason may be that older family formation migrants have accumulated more source specific human capital which could make it optimal for them to return. However, for Moroccan migrants the age at entry seems irrelevant in explaining their return behaviour.

Finding a job or receiving benefits (mainly unemployment benefits) greatly reduces the chance of leaving, especially for migrants from less developed countries. This shows that, even for family migrants, labour market participation is a good measure of assimilation in the country and therefore leads to less return. In Section 7 we investigate the importance of labour market dynamics in more detail. The impact of income on return for family is less important and does not exhibit a U-shape, with both high- and low income migrants leaving fast, as found by (Bijwaard and Wahba (2013)) for labour migrants. Owning a house reduces the return, but not for 
Moroccans. Note that all these individual characteristics of the migrants are, potentially, time-varying as we observe their value on a monthly basis.

The EU 15 indicator, the religion and distance of the country of birth are all time constant. The freedom of movement of DC-migrants from the EU 15 countries make them really more mobile. Despite that for migrants from Muslim countries assimilation into the Dutch society is more difficult, because their culture differs substantially from the Dutch culture, they are more prone to stay. The distance of the home country from the Netherlands, another indicator of the cultural similarity, only has a minor impact on return. ${ }^{6}$.

The effect of the business cycle, captured by the (changing over time) national employment rate, is only apparent for DC and LDC migrants. These migrants are less prone to leave in an economic crisis. We find some moderate entry selection for DC migrants and Turkish migrants. The estimated baseline hazard tells us that the hazard of leaving increases with the length of stay, the most for LDC migrants and the least for Moroccan migrants.

\section{Insert Table 3 here}

\subsection{Divorce process}

The economic approach to marriage is usually based on the assumption that couples marry and remain together when the net gains from marriage are greater than those from being single, Becker (1974a) (Becker (1974a), Becker (1974b), Becker (1991)). Even if the migration decision is motivated by maximization of family income, one of the partners may benefit more from the move than the other, (Mincer (1978)). This may change the gains from marriage for the 'tied-mover'. Moving is also a stressful life event and therefore increases the chances of divorce, (Flowerdew and Al-Hamad (2004)). The impact of factors that influence the divorce hazard in our data are reported in Table 4.

In the literature age at marriage is commonly found to have a strong inversely related impact on divorce, a result that has been interpreted as a 'maturity effect', see a.o. (Lyngstad and Jalovaara (2010)). However, we find for all (except LDC) migrant groups that the age of entry is negatively related to marriage disruption. Migrating at a higher age seems to jeopardize marriage. This might be a 'poor match effect' which suggest that with increasing age a woman may revise her expectations downward and settle for a less optimal match to secure any offspring, Becker et al (1977)) and (Lehrer (2008)). Males from IDC, LDC and Turkey are more likely to divorce (than females from these groups), while males from Morocco are less likely to divorce. Children are usually union specific capital, Becker et al (1977)). This implies that the benefits gained from having children is bigger when the parents live together than when they are separated. We find for all five groups that children have a stabilizing effect on marriage and the effect is the largest for migrants from Morocco.

\footnotetext{
${ }^{6}$ Because most less developed countries are far away from the Netherlands the majority of LDC countries is a long distance country and we therefore changed the reference distance for this group.
} 
According to the specialization model of Becker et al (1977)) a marriage gains the most when one of the spouses specializes in paid work, and the other in household work. Given that the sponsor of the family migrant should have sufficient income, see Section 3, we would expect to see a higher divorce risk when the family migrant enters the labour market or when the migrant has a high income. However, this specialization model seems anachronistic in contemporary Western countries and has therefore been criticized. (Oppenheimer (1997)) formalized a model that values a marriage more when both partners are working. (Doiron and Mendolia (2012)) emphasize that job loss triggers union dissolution. Our results, consistent with (Doiron and Mendolia (2012)) findings, show that family migrants who are on benefits, i.e. after some period of employment, have (much) larger divorce hazards. Consistent with the specialization-model is that employment also increases the divorce rate. The U-shaped effect of income on divorce, seem to support both the specialization model, no income leads to lower divorce hazards, and the (Oppenheimer (1997)) model, high income leads to lower divorce hazards.

Migrants from muslim countries have lower divorce rates. In economic downfalls the chances of income loss for the whole family increases which leads to higher divorce rates. Contrary to the common assumption we find that for all migrant groups the divorce risk increases with the length of the marriage. However, most studies of divorce rates do not include unobserved heterogeneity. It is well known that ignoring unobserved heterogeneity leads to spurious negative duration dependence.

\section{Insert Table 4 here}

\subsection{Re-marriage process}

The literature on remarriage has expanded during the past few decades. We only mention two important economics articles on remarriage. Becker et al (1977)) theorized that specialization between men and women also leads to remarriage. (Chiswick and Lehrer (1990)) focus on the influence of marriage-specific human capital on the remarriage rate.

Our results, reported in Table 5, are often contrary to those found in the literature. The relatively few significant variables might be due to the limited number of remarriages (due to the limited time frame). Although the literature states that women benefit more from remarriage we do not find any significant difference in the remarriage rate by gender. ${ }^{7}$ Only for DC migrants remarriages we confirm that children (from a previous union) have a negative impact on the probability to remarriage. Income does not seem to play a major role in explaining remarriage. When a migrant is on social benefits her/his chances to remarry is (much) lower. Such a migrant is considered a less attractive match on the marriage market. We also find that employment reduces the remarriage rate. Employment creates for women an 'independence' effect that removes the need to remarry. In an economic crisis the migrants from less developed countries, Turkey and Morocco are more prone to remarry. We hardly find

\footnotetext{
7 The literature often posits differential effects of human capital variables on remarriage by gender. Our number of remarriages are too small to estimate separate remarriage rates by gender.
} 
a change in the remarriage rate with the length of the divorce, the duration dependence. Only for IDC migrants we find a negative relation between divorce length and remarriage.

\section{Insert Table 5 here}

\subsection{The effect of divorce and remarriage on return}

The estimated effects of divorce and remarriage on return migration hazard, $\gamma_{d}$ and $\gamma_{r}$ in (3), are reported in Table 6 and 7. Table 6 demonstrates the importance of divorce on return. Only for migrants from developed countries the end of a marriage does not significantly increase return of family migrants. A possible explanation for this is that these migrants are more prone to migrate anyway and their residence status does not depend on their marital status. Another explanation is that the rate of integration in the host country is related to the development of the source country. When a migrant is well integrated, she is more (financially) independent and therefore the 'need' for remigration will be less upon divorce. The effect of divorce for migrants from the other groups is rather large, e.g. a family migrant from a LDC is $6.5\left(=e^{1.875}\right)$ times more likely to leave when she divorces. These non-DC migrants are in general less integrated and female migrants financially depend more on their husband. The effect of divorce on return does not change with the length of the divorce, as the results of model 2 show no significant duration effects. Further permitting the effect to vary across observed characteristics of the migrants (Model 3) reveals that the impact of divorce on return is larger for young migrants and for migrants without income (especially for Turks and Moroccans). Younger migrants are usually more mobile and have accumulated less source specific capital and are therefore more prone to leave when they divorce. For financially dependent migrants without income, especially those from poor countries, a divorce is an obvious reason to leave. Only for Turkish migrants we find a gender effect with Turkish males affected less by divorce than Turkish females.

\section{Insert Table 6 here}

Finding a new partner after divorce and remarry in The Netherlands is only for DC-migrants a bonding (to the Netherlands) event. For family migrants from poor countries remarriage induces them to leave, see Table 7 . This is probably because many of these migrants find a spouse from their country of origin and then return. DC-migrants (re)marry more often with natives. Unfortunately, our data does not contain information on the (new) partner of the family migrant. So, we are unable to test this hypothesis, but from aggregated data we know that this is true. We do not find evidence that the effect of remarriage changes with the time since the new marriage had been formed (model 2). The results from model 3, that allows the effect of remarriage on return to change with observed characteristics of this marriage, reveal that the negative effect of remarriage for DC migrants is fully driven by the effect on female migrants.

\section{Insert Table 7 here}




\section{Quantification of Impacts}

Next we illustrate, using microsimulation studies, the impact of divorce, remarriage and employment patterns on migrants' return probabilities. ${ }^{8}$ These simulations are based on synthetic cohorts of family migrants, all entering at the same time, and use the estimated parameters of model 3 and the observed distribution of the characteristics (control variables) at entry into the Netherlands of the family migrants in our sample as input. The synthetic cohort consists of 50,000 migrants. For each simulation round, we draw a vector of parameter estimates assuming that the estimated coefficients are normally distributed around the point estimates with a variance-covariance matrix equal to the estimated one. Next, we simulate the migration process for each member of the synthetic cohort using the implied migration hazards. We postulate several divorce, remarriage and employment profiles and consider their impact on the average return probability. We repeat the simulations 100 times, which allows us to calculate confidence intervals around the average change in return probability of each profile.

In order to assess the effect of the timing of a divorce, we consider divorces that start at 24, 36 and 48 months after entry into the Netherlands. Figure 5 displays, for each country group separately, the change in return probability of divorced migrants compared to the return probability of migrants who remain married their full stay in the Netherlands. The figures re-illustrate the large impact of divorce on return (except for DC migrants) we reported in Table 6 and the differences by migrant group. Migrants from LDC's and Morocco are affected most by divorce, they have five years after divorce a more than $30 \%$ higher chance that they have left. Only for Moroccan migrants the timing of divorce seems to matter.

Next, we consider migrants who remarry after a divorce that lasted for two years (if they are still in the country). This allows us to quantify the (long run) impact of divorce and remarriage on return. The results of these simulations are depicted in Figure 6. Because we found for most migrant groups (except for DC migrants) that remarriage induces them to leave (see Table 7) the return probability is in the long run is closer to the return probability of always married migrants. However, the return probabilities never completely converge to those levels (except for maybe the IDC-migrants). Remarried DC-migrants have a lower return probability than always married DC-migrants.

Finally, to assess the impact of employment timing on the return, we consider employment at starting 24,36 or 48 months after entry into the Netherlands. The results of these simulations are shown in Figure 7. Across all migrant groups we find that employment greatly reduces the chance that a migrant returns. The largest effects are found for DC-migrants, who have a $40 \%$ lower chance to have returned after ten years when they found a job two years after arrival. Despite the large impact of employment the impact of divorce on return is higher for Turkish and Moroccan family migrants. Those migrants have a low return rate and employment cannot increase that much more, while a divorce induces them to leave.

\footnotetext{
${ }^{8}$ We also include employment profiles because labour market behaviour is also an important factor in explaining return, see Table 3. Bijwaard et al (2013)) investigate the relation between labour market behaviour and return in more detail. However, they focus on labour migrants only.
} 


\section{Insert Figure 5 here \\ Insert Figure 6 here \\ Insert Figure 7 here}

\section{Robustness checks}

\subsection{Selectivity Bias}

We briefly illustrate the consequences of ignoring the endogeneity issue induced by the correlations between the unobservable heterogeneity terms $\left(v_{d}, v_{r}, v_{m}\right)$ given by distribution $G$. The 'timing-of-events' model nests the conventional (M)PH models for the return hazard. The PH model ignores unobservable heterogeneity altogether, $\theta_{m}^{P H}\left(t \mid t_{d}, t_{r}, x_{m}(t)\right)=\exp \left(x_{m}(t) \beta_{x}^{m}+I_{d}(t) \gamma_{d}+I_{r}(t) \gamma_{r}\right)$, whereas the MPH model, $\theta_{m}^{M P H}\left(t \mid t_{d}, t_{r}, x_{m}(t), v_{m}\right)=v_{m} \theta_{m}^{P H}\left(t \mid t_{d}, t_{r}, x_{m}(t)\right)$ ignores the correlation between $\theta_{m}$ and $\theta_{d}$ and $\theta_{r}$, see (3). We quantify the resulting selectivity biases in terms of the estimated effects of divorce and remarriage on the return migration hazards. For the sake of brevity, we illustrate the issue in the context of Model 1, i.e. the estimate of the constant effect given by $\gamma=\left(\gamma_{d}, \gamma_{r}\right)$. Table 8 reports the results.

\section{Insert Table 8 here}

The simple PH model already shows that for all migrant groups the incidence of a divorce significantly increases return probabilities. Extending this model to incorporate (uncorrelated) unobserved heterogeneity has only a small effect on the estimated effect. However, taking into account the correlated unobserved heterogeneity in the timing-of-events model has a substantial effect on the estimates. For DC-migrants the significance of the divorce effect disappears and the remarriage effect becomes twice as large. For LDC-migrants the divorce effect doubles and the remarriage-effect become significant. We conclude that ignoring the endogeneity issue would result in substantial selectivity biases.

\subsection{Sensitivity checks}

The grouping of the migrants (except for Turkish and Moroccan migrants) is based on the human development index of the UN. Although the cut-off points are close to the ones the UN uses in their reporting, they might influence the results. The UN distinguishes four groups of countries: (i) Countries with 'Very high human development' having an HDI $\geq 0.793$; (ii) Countries with 'High human development' having an HDI running from 0.698 to 0.783 ; (iii) Countries with 'Medium human development' having an HDI running from 0.522 to 0.696 and (iv) Countries with 'Low human development' having an HDI $<0.522$. We consider five alternative groupings

1. Developed countries are the countries with very high human development; Intermediate developed countries are countries with medium and high human development and the less developed countries are the countries with low human development. 
2. Developed countries are the countries with very high human development; Intermediate developed countries are countries with high human development and the less developed countries are the countries with medium and low human development.

3. Developed countries are the countries with an HDI above 0.75 ; Intermediate developed countries are countries with an HDI between 0.6 and 0.75 and the less developed countries are the countries with HDI below 0.6.

4. Developed countries are the countries with very high human development; Intermediate developed countries are countries with high human development and medium developed countries with HDI above 0.6 and the less developed countries are the countries with low human development and the medium developed countries with HDI below 0.6 (including e.g. Iraq and India).

5. Developed countries are the countries with very high human development; Intermediate developed countries are countries with high human development and medium developed countries with HDI above 0.65 and the less developed countries are the countries with low human development and the medium developed countries with HDI below 0.65 (including e.g. Iraq, India, Indonesia and South Africa).

Table 9 reports the the results of model 1 , constant divorce and remarriage effect, for different cut-off points. These estimated effects are very similar to the results using the original HDI cut-off points. Only cut-off 2 gives slightly different results for the LDC's. However, this cut-off is rather extreme as it assigns all countries with medium human development to the less developed countries.

\section{Insert Table 9 here}

\section{Conclusion}

Most previous studies on migration have neglected the substantial extent of nonlabour immigration. Indeed, family migrants constitute a large fraction of the inflow of immigrants. Although they are less prone to remigrate than labour migrants, a substantial proportion of them leaves the host country eventually. This is most apparent for family migrants from developed countries (DC). Within ten years more than fifty percent of those family migrants have left.

For family migrants their main migration motive is to join their (future) spouse. However, a substantial proportion of these marriages end in a divorce, just as with any other marriages in the Western world. The return migration behaviour of these family migrants is more susceptible to changes in their marital status than labour migrants. Marriage dissolution and remarriage are likely to induce a move and therefore induce return migration. Despite the importance of temporary immigration and marriage instability, the interdependence of divorce, remarriage and immigration durations has received little attention in the empirical literature. In this paper we have addressed this issue using a unique Dutch administrative panel of the entire population of recent family immigrants in which we observe information on the timing of migration moves, timing of marital status changes, labour market changes and income changes. 
The large size of the data enables us to estimate separate models for distinct immigrant groups, defined by the human development index of the UNDP, and we have shown the importance of controlling for observable migrant heterogeneity.

An empirical challenge arises from the potential correlation between the divorce, remarriage- and migration processes which, if present and ignored, confounds the effect of marital changes on return. The timing of events method enables us to estimate the effects of the timing and path of these marital processes on migration durations, while we controled for (possibly correlated) unobservable heterogeneity. Simpler (mixed) proportional hazard models which ignore correlations among marital and migration processes are shown to exhibit substantial selection biases. We also discuss when the obtained effects have a causal interpretation.

Overall, we have found that divorce shortens the migration duration, with the largest impact for migrants from less developed countries. Most migrants from developed countries have more freedom of movement and depend less on their marital status for a valid living permission and are, therefore, less prone to leave the country after a divorce. Migrants from more developed countries also have a higher chance to integrate into the Dutch society and (the women) are therefore more independent after divorce. When we permit the effect to vary across observed characteristics of the migrants it becomes apparent that mainly young and low income migrants are affected by divorce.

Finding a new partner, after divorce, and remarry in the Netherlands induces migrants from less developed countries to leave. This is probably because many of them find a spouse from their country of origin. Migrants from developed countries marry more often a native which makes them (especially women) more prone to stay after remarriage.

The impact of divorce on return might be confounded by marriage of convenience, a marriage contracted for the sole purpose of enabling the person concerned to enter or reside in the Netherlands. Although there is no national registration, estimates by the Immigration office, (van der Wolff (2012)), indicate that no more than $2 \%$ of the marriages are suspectable marriages of convenience. Thus, we do not expect that the possibility of such marriages will affect our results much.

The impact of the timing of divorce and remarriage on the duration of stay is qualified by a couple of experiments. These experiments show that only for Moroccan migrants the timing of divorce seems to matter, but remarriage removes this timing effect. In the end a divorce lead to a $30 \%$ to $40 \%$ higher return for migrants from less developed countries.

Currently, we do not have spousal information, neither whether the partner is a native nor what the labour market situation of the partner is. However, for migrants (first and second generation) from LDC's the marriage rate to natives is low, see (Kalmijn and van Tubergen (2006)) and (van Tubergen and Maas (2007)). An important avenue for further research is to view the behaviour of family migrants in a household perspective. With information on the characteristics and the behaviour of the partner linked to the individual migrant opens the opportunity to explore the interlinkage between the partners and its impact on migration behaviour. 
Acknowledgements This research is based on van Doeselaar's Master thesis in Econometrics at Tilburg University. Financial support from the NORFACE research programme on Migration in Europe - Social, Economic, Cultural and Policy Dynamics is gratefully acknowledged. We thank Statistics Netherlands, Ruben van Gaalen in particular, for data support. We thank Arthur van Soest and Jaap Abbring for helpful comments.

We would also thank two anonymous referees and the editor-in-chief, Klaus Zimmermann, who provided very valuable inputs for a substantial revision of an earlier draft.

\section{References}

[Abbring and van den Berg (2003)] Abbring JH, van den Berg GJ (2003) The nonparametric identification of treatment effects in duration models. Econometrica $71: 1491-1517$

[Aydemir (2011)] Aydemir A (2011) Immigrant selection and short-term labor market outcomes by visa category. J Popul Econ 24:451-475

[Aydemir and Robinson (2008)] Aydemir A, Robinson C (2008) Global labor markets, return and onward migration. Can J Econ 41:1285-1311

[Becker (1974a)] Becker GS (1974a) A theory of marriage: Part I. J Pol Econ 81:813-846

[Becker (1974b)] Becker GS (1974b) A theory of marriage: Part II. J Pol Econ 81:S11-S26

[Becker (1991)] Becker GS (1991) A treatise on the Family. Enlarged edition. Harvard Univeristy Press, Cambridge MA

[Becker et al (1977)] Becker GS, Landes EM, Michael RT (1977) An economic analysis of marital instability. J Pol Econ 85:1141-1187

[Bijwaard (2010)] Bijwaard GE (2010) Immigrant migration dynamics model for The Netherlands. J Popul Econ 23:1213-1247

[Bijwaard and Wahba (2013)] Bijwaard GE, Wahba J (2013) Do high-income or low-income immigrants leave faster? Discussion Paper 13-13, NORFACE

[Bijwaard et al (2013)] Bijwaard GE, Schluter C, Wahba J (2013) The impact of labour market dynamics on the return-migration of immigrants. Rev Econ Stat forthcoming

[Borjas (1999)] Borjas GJ (1999) The economic analysis of immigration. In: Ashenfelter O, Card D (eds) Handbook of Labor Economics, Volume 3A, Amsterdam: North-Holland, chap 28

[Borjas and Bratsberg (1996)] Borjas GJ, Bratsberg B (1996) Who leaves? The outmigration of the foreignborn. Rev Econ Stat 78:165-176

[Boyle et al (2001)] Boyle P, Cooke T, Halfacree K, Smith D (2001) A cross-national comparison of the impact of family migration on women's employment status. Demography 38(2):201-213

[Boyle et al (2008)] Boyle PJ, Kulu H, Cooke T, Gayle V, Mulder CH (2008) Moving and union dissolution. Demography 45:209-222

[Chiswick and Lehrer (1990)] Chiswick CU, Lehrer EL (1990) On marriage-specific human capital its role as a determinant of remarriage. J Popul Econ 3:193-213 
[Crépon et al (2012)] Crépon B, Ferracci M, Fougére D (2012) Training the unemployed in France: How does it affect unemployment duration and recurrence? Ann Econ Stat 108:175-200

[Doiron and Mendolia (2012)] Doiron D, Mendolia S (2012) The impact of job loss on family dissolution. J Popul Econ 25:367-398

[Dustmann (1995)] Dustmann C (1995) Return migration: The European experience. Econ Pol 22:214-250

[Dustmann (2003)] Dustmann C (2003) Children and return migration. J Popul Econ $16: 815-830$

[Dustmann and Weiss (2007)] Dustmann C, Weiss Y (2007) Return migration: Theory and empirical evidence. Brit J Indus Rel 45:236-256

[Edin et al (2000)] Edin PA, Lalonde RJ, Åslund O (2000) Emigration of immigrants and measures of immigrant assimilation: Evidence from Sweden. Swed Econ Rev 7:163-204

[Flowerdew and Al-Hamad (2004)] Flowerdew R, Al-Hamad A (2004) The relationship between marriage, divorce and migration in a British data set. J Ethn Mig Studies 30:339-351

[Gibson and McKenzie (2011)] Gibson J, McKenzie D (2011) The microeconomic determinants of emigration and return migration of the best and brightest: Evidence from the Pacific. J Dev Econ 95:18-29

[Hill (1987)] Hill JK (1987) Immigrant decisions concerning durations of stay and migratory frequency. J Dev Econ 25:221-234

[Jasso and Rosenzweig (1982)] Jasso G, Rosenzweig MR (1982) Estimating the emigration rates of legal immigrants using administrative and survey data: The 1971 cohort of immigrants to the US. Demography 19:279-290

[Jasso and Rosenzweig (1995)] Jasso G, Rosenzweig MR (1995) Do immigrants screened for skills do better than family reunification immigrants? Int Mig Rev 29:85-111

[Jensen and Pedersen (2007)] Jensen P, Pedersen PJ (2007) To stay or not to stay? out-migration of immigrants from Denmark. Int Mig 45:87-113

[Kalmijn and van Tubergen (2006)] Kalmijn M, van Tubergen F (2006) Ethnic intermarriage in the Netherlands: Confirmations and refutations of accepted insights. Eur J Popul 22:371-397

[Lehrer (2008)] Lehrer EL (2008) Age at marriage and marital instability: Revisiting the BeckerLandesMichael hypothesis. J Popul Econ 21:463-484

[Lyngstad and Jalovaara (2010)] Lyngstad TH, Jalovaara M (2010) A review of the antecedents of union dissolution. Demo Res 23:257-292

[Miller (1999)] Miller P (1999) Immigration policy and immigrant quality: The Australian points system. Am Econ Rev 89:192-197

[Mincer (1978)] Mincer J (1978) Family migration decisions. J Pol Econ 86:749773

[Nivalainen (2004)] Nivalainen S (2004) Determinants of family migration: Short moves vs. long moves. J Popul Econ 17:157-175

[Oppenheimer (1997)] Oppenheimer VK (1997) Women's employment and the gain to marriage: The specialization and trading model. Ann Rev Soc 23:431-453 
[Osikominu (2013)] Osikominu A (2013) Quick job entry or long-term human capital development? the dynamic effects of alternative training schemes. Rev Econ Stud 80:313-342

[Rodriguez-Planas and Vegas (2011)] Rodriguez-Planas N, Vegas R (2011) Moroccans' assimilation in Spain: Family-based versus labor-based migration. Mid East Dev J 3:119-139

[Sandell (1977)] Sandell S (1977) Women and the economics of family migration. Rev Econ Stat 59(4):406-414

[UNDP (2011)] UNDP (2011) Human Development Index. http://hdr . undp. org/en/media/HDR_2011_EN_Table1.pdf. Accessed 12 March 2012

[Van den Berg (2001)] Van den Berg GJ (2001) Duration models: Specification, identification, and multiple duration. In: Heckman J, Leamer E (eds) Handbook of Econometrics, Volume V, Amsterdam: North-Holland, chap 55, pp 3381-3460

[van der Wolff (2012)] van der Wolff AC (2012) Misuse of the right of family reunification: The Netherlands contribution. EMN studies, Dutch National Contact Point for the European Migration Network

[van Tubergen and Maas (2007)] van Tubergen F, Maas I (2007) Ethnic intermarriage among immigrants in the Netherlands: An analysis of population data. Soc Science Res 36:1065-1086 
Table 1 Descriptive Dynamics

\begin{tabular}{|c|c|c|c|c|c|c|}
\hline & All & DC & IDC & LDC & Turkey & Morocco \\
\hline $\mathrm{N}$ & 100,392 & 35,629 & 14,917 & 11,570 & 20,091 & 18,185 \\
\hline Stayer $^{1}$ & $79.3 \%$ & $64.9 \%$ & $82.7 \%$ & $81.7 \%$ & $89.7 \%$ & $91.6 \%$ \\
\hline $\begin{array}{l}<1 \text { year } \\
1-2 \text { years } \\
2-3 \text { years } \\
3-4 \text { years } \\
4-5 \text { years } \\
>5 \text { years } \\
\text { average [months] }\end{array}$ & $\begin{array}{l}17.0 \% \\
24.7 \% \\
19.5 \% \\
14.0 \% \\
10.2 \% \\
14.6 \% \\
33.8\end{array}$ & $\begin{array}{l}\quad \text { Leng } \\
17.3 \% \\
26.5 \% \\
21.4 \% \\
14.4 \% \\
9.5 \% \\
10.9 \% \\
31.7\end{array}$ & $\begin{array}{l}\text { of stay c } \\
14.4 \% \\
22.1 \% \\
18.7 \% \\
13.7 \% \\
12.1 \% \\
19.1 \% \\
37.2\end{array}$ & $\begin{array}{l}\text { return } m \\
14.8 \% \\
20.5 \% \\
15.7 \% \\
11.7 \% \\
11.6 \% \\
25.7 \% \\
40.1\end{array}$ & $\begin{array}{l}\text { ration } \\
18.1 \% \\
22.5 \% \\
17.9 \% \\
15.8 \% \\
10.0 \% \\
15.8 \% \\
34.6\end{array}$ & $\begin{array}{l}19.6 \% \\
22.7 \% \\
13.1 \% \\
12.4 \% \\
11.5 \% \\
20.7 \% \\
36.2\end{array}$ \\
\hline $\begin{array}{l}\text { always married }{ }^{2} \\
\text { once divorced } \\
\text { once remarried }\end{array}$ & $\begin{array}{l}91.6 \% \\
8.3 \% \\
1.1 \%\end{array}$ & $\begin{array}{l}94.2 \% \\
5.8 \% \\
0.8 \%\end{array}$ & $\begin{array}{l}\text { elationst } \\
88.6 \% \\
11.2 \% \\
1.4 \%\end{array}$ & $\begin{array}{l}\text { Dynam } \\
93.4 \% \\
6.6 \% \\
0.4 \%\end{array}$ & $\begin{array}{l}90.4 \% \\
9.5 \% \\
1.5 \%\end{array}$ & $\begin{array}{l}89.0 \% \\
10.9 \% \\
1.8 \%\end{array}$ \\
\hline $\begin{array}{l}<1 \text { year } \\
1-2 \text { years } \\
2-3 \text { years } \\
3-4 \text { years } \\
4-5 \text { years } \\
>5 \text { years } \\
\text { average [months] }\end{array}$ & \begin{tabular}{l|}
$6.9 \%$ \\
$11.5 \%$ \\
$13.7 \%$ \\
$21.6 \%$ \\
$20.9 \%$ \\
$25.5 \%$ \\
45.7
\end{tabular} & $\begin{array}{l}\text { Le } \\
12.2 \% \\
12.4 \% \\
13.0 \% \\
18.0 \% \\
20.1 \% \\
24.3 \% \\
43.1\end{array}$ & $\begin{array}{l}\text { th of } m a \\
5.4 \% \\
14.3 \% \\
17.5 \% \\
18.7 \% \\
19.0 \% \\
25.1 \% \\
44.8\end{array}$ & $\begin{array}{l}\text { iage at } d \\
5.5 \% \\
10.6 \% \\
10.2 \% \\
16.7 \% \\
21.4 \% \\
35.8 \% \\
50.4\end{array}$ & $\begin{array}{l}\text { orce } \\
4.5 \% \\
10.6 \% \\
14.6 \% \\
26.3 \% \\
19.7 \% \\
24.3 \% \\
46.1\end{array}$ & \begin{tabular}{l|}
$5.4 \%$ \\
$9.3 \%$ \\
$11.6 \%$ \\
$25.1 \%$ \\
$24.4 \%$ \\
$24.2 \%$ \\
47.2
\end{tabular} \\
\hline
\end{tabular}

${ }^{1}$ Stayers are migrants who remain in the country till the end of the observation period.

${ }^{2}$ Percentage of migrants that is married through the whole stay in the country. 
Table 2 Descriptive Dynamics: Divorced immigrants who leave.

\begin{tabular}{|c|c|c|c|c|c|c|}
\hline & All & $\mathrm{DC}$ & IDC & LDC & Turkey & Morocco \\
\hline \multirow[t]{2}{*}{ Divorced at emigration $^{1}$} & $5.7 \%$ & $2.9 \%$ & $7.6 \%$ & $5.9 \%$ & $12.8 \%$ & $15.2 \%$ \\
\hline & \multicolumn{6}{|c|}{ Preceding marriage duration $^{2}$} \\
\hline$<1$ year & $11.7 \%$ & $11.4 \%$ & $7.1 \%$ & $4.0 \%$ & $16.7 \%$ & $14.5 \%$ \\
\hline $1-2$ years & $23.5 \%$ & $24.4 \%$ & $25.0 \%$ & $17.7 \%$ & $22.4 \%$ & $25.2 \%$ \\
\hline $2-3$ years & $18.6 \%$ & $19.1 \%$ & $20.9 \%$ & $11.3 \%$ & $21.2 \%$ & $16.7 \%$ \\
\hline $3-4$ years & $18.4 \%$ & $16.1 \%$ & $21.4 \%$ & $19.4 \%$ & $19.3 \%$ & $18.0 \%$ \\
\hline $4-5$ years & $13.9 \%$ & $16.6 \%$ & $9.2 \%$ & $24.2 \%$ & $8.0 \%$ & $15.0 \%$ \\
\hline$>5$ years & $13.9 \%$ & $12.5 \%$ & $16.3 \%$ & $23.4 \%$ & $12.5 \%$ & $10.7 \%$ \\
\hline \multirow[t]{2}{*}{ average [months] } & 35.8 & 35.4 & 36.9 & 45.0 & 33.1 & 33.8 \\
\hline & \multicolumn{6}{|c|}{ Current divorce duration $^{2}$} \\
\hline$<2$ year & $70.8 \%$ & $73.1 \%$ & $66.3 \%$ & $66.1 \%$ & $72.7 \%$ & $71.4 \%$ \\
\hline $2-3$ years & $13.6 \%$ & $11.9 \%$ & $15.8 \%$ & $14.5 \%$ & $12.5 \%$ & $15.0 \%$ \\
\hline$>3$ years & $15.6 \%$ & $15.0 \%$ & $17.9 \%$ & $19.4 \%$ & $14.8 \%$ & $13.7 \%$ \\
\hline average [months] & 19.0 & 18.2 & 19.9 & 20.1 & 18.9 & 19.1 \\
\hline
\end{tabular}

1 Percentage of return migrants.

${ }^{2}$ Percentage of migrants returned while divorced. 
Table 3 Estimated effect of control variables on return migration hazards.

\begin{tabular}{l|ccccc}
\hline & DC & IDC & LDC & Turkey & Morocco \\
\hline Male & $0.129^{* *}$ & $0.469^{* *}$ & $0.359^{* *}$ & $0.691^{* *}$ & $0.951^{* *}$ \\
\# of children & $-0.293^{* *}$ & $-0.420^{* *}$ & $-0.266^{* *}$ & $-0.467^{* *}$ & $-0.455^{* *}$ \\
aged 18-20 & $-0.808^{* *}$ & $-0.744^{* *}$ & $-0.640^{* *}$ & $-0.821^{* *}$ & -0.064 \\
aged 21-25 & $-0.362^{* *}$ & $-0.453^{* *}$ & $-0.340^{* *}$ & $-0.455^{* *}$ & -0.020 \\
aged 35-50 & $0.076^{* *}$ & -0.027 & -0.033 & $0.166^{+}$ & 0.122 \\
aged >50 & $-0.154^{* *}$ & -0.090 & -0.336 & $0.470^{* *}$ & 0.312 \\
No income & 0.013 & $0.234^{* *}$ & $-0.177^{+}$ & -0.042 & $-0.316^{* *}$ \\
Low income & $-0.388^{* *}$ & $-0.259^{+}$ & -0.217 & -0.040 & 0.095 \\
High income & $0.561^{* *}$ & $0.816^{* *}$ & $0.600^{+}$ & 0.480 & -0.300 \\
house owned & $-0.388^{* *}$ & $-0.271^{* *}$ & $-0.161^{+}$ & $-0.226^{* *}$ & -0.012 \\
employed & $-1.971^{* *}$ & $-2.634^{* *}$ & $-3.368^{* *}$ & $-2.210^{* *}$ & $-1.923^{* *}$ \\
Onbenefit & $-1.790^{* *}$ & $-1.591^{* *}$ & $-1.956^{* *}$ & $-1.652^{* *}$ & $-1.743^{* *}$ \\
EU15 & $0.723^{* *}$ & - & - & - & - \\
Muslim Country & $-0.352^{* *}$ & $-0.417^{* *}$ & $-0.714^{* *}$ & - & - \\
Christian Country & -0.003 & $0.681^{* *}$ & -0.109 & - & - \\
medium distance & $-0.367^{* *}$ & $-0.337^{+}$ & $-0.299^{* *}$ & - & - \\
long distance & $0.680^{* *}$ & $-0.474^{* *}$ & - & - & - \\
Nat. Unemployment rate & $-0.038^{* *}$ & 0.041 & $-0.078^{* *}$ & 0.042 & -0.050 \\
Unemployment rate at entry & $0.076^{* *}$ & 0.014 & -0.012 & $0.071^{+}$ & 0.037 \\
1-2 years & $0.949^{* *}$ & $1.111^{* *}$ & $0.998^{* *}$ & $0.903^{* *}$ & $0.822^{* *}$ \\
2-3 years & $1.182^{* *}$ & $1.352^{* *}$ & $1.270^{* *}$ & $0.914^{* *}$ & $0.501^{* *}$ \\
3-4 years & $1.226^{* *}$ & $1.365^{* *}$ & $1.407^{* *}$ & $1.009^{* *}$ & $0.622^{* *}$ \\
$>$ 4 years & $1.199^{* *}$ & $1.674^{* *}$ & $2.180^{* *}$ & $0.847^{* *}$ & $0.826^{* *}$ \\
\hline
\end{tabular}

Notes: SE in parentheses. ${ }^{+}: p<0.05$ and $^{* *}: p<0.01$. Sector dummies while employed are also included 
Table 4 Estimated effect of control variables on divorce hazards.

\begin{tabular}{l|ccccc}
\hline & DC & IDC & LDC & Turkey & Morocco \\
\hline Male & -0.019 & $0.527^{* *}$ & $0.422^{* *}$ & $0.208^{* *}$ & $-0.225^{* *}$ \\
\# of children & $-0.290^{* *}$ & $-0.300^{* *}$ & $-0.453^{* *}$ & $-0.643^{* *}$ & $-1.036^{* *}$ \\
aged 18-20 & $-0.261^{+}$ & $-0.378^{* *}$ & -0.254 & $-0.474^{* *}$ & $-0.520^{* *}$ \\
aged 21-25 & -0.047 & $-0.323^{* *}$ & -0.034 & $-0.466^{* *}$ & $-0.245^{* *}$ \\
aged 35-50 & $0.129^{+}$ & $0.235^{* *}$ & -0.115 & $0.385^{* *}$ & $0.244^{* *}$ \\
aged > 50 & -0.125 & 0.028 & -0.203 & 0.083 & -0.324 \\
No income & $-0.766^{* *}$ & $-0.754^{* *}$ & $-0.859^{* *}$ & $-0.724^{* *}$ & $-0.743^{* *}$ \\
Low income & 0.109 & -0.068 & -0.038 & -0.077 & -0.036 \\
High income & $-0.606^{* *}$ & $-1.027^{* *}$ & -0.931 & -0.343 & 0.167 \\
employed & 0.055 & $0.473^{* *}$ & $0.323^{* *}$ & 0.108 & $0.285^{* *}$ \\
On benefit & $0.905^{* *}$ & $1.237^{* *}$ & $0.790^{* *}$ & $0.548^{* *}$ & $1.063^{* *}$ \\
Muslim Country & $-0.215^{+}$ & $-1.074^{* *}$ & $-0.345^{* *}$ & - & - \\
Christian Country & $0.193^{* *}$ & $-1.038^{* *}$ & 0.216 & - & - \\
medium distance & $0.450^{* *}$ & 0.073 & 0.092 & - & - \\
long distance & 0.091 & -0.325 & - & - & - \\
Nat. Unemployment rate & $0.083^{* *}$ & 0.031 & 0.074 & $0.113^{* *}$ & $0.096^{* *}$ \\
Unemployment rate at entry & 0.037 & -0.024 & $0.150^{* *}$ & 0.052 & 0.013 \\
2-3 years & $0.350^{* *}$ & $0.588^{* *}$ & $0.323^{+}$ & $0.785^{* *}$ & $0.543^{* *}$ \\
3-4 years & $0.866^{* *}$ & $0.814^{* *}$ & $0.977^{* *}$ & $1.576^{* *}$ & $1.535^{* *}$ \\
$>$ 4 years & $1.266^{* *}$ & $1.132^{* *}$ & $1.541^{* *}$ & $1.695^{* *}$ & $1.964^{* *}$ \\
\hline
\end{tabular}

Notes: SE in parentheses. ${ }^{+}: p<0.05$ and $^{* *}: p<0.01$. 
Table 5 Estimated effect of control variables on re-marriage hazards.

\begin{tabular}{l|ccccc}
\hline & DC & IDC & LDC & Turkey & Morocco \\
\hline Male & -0.322 & -0.068 & 0.165 & 0.075 & -0.019 \\
\# of children & $-0.146^{+}$ & -0.007 & -0.231 & 0.014 & 0.023 \\
aged 18-20 & 0.312 & -0.188 & 0.879 & -0.310 & -0.287 \\
aged 21-25 & -0.065 & -0.193 & 0.215 & 0.043 & -0.240 \\
aged 35-50 & 0.080 & -0.135 & -0.202 & -0.342 & -0.270 \\
aged $>$ 50 & -0.490 & $-2.436^{+}$ & -0.576 & -1.173 & -0.707 \\
No income & $0.640^{* *}$ & 0.057 & 0.328 & -0.189 & 0.256 \\
Low income & 0.105 & 0.200 & 0.122 & -0.014 & -0.215 \\
High income & -0.419 & -0.813 & $1.491^{+}$ & 0.194 & -0.410 \\
employed & -0.300 & $-0.542^{* *}$ & $-1.178^{* *}$ & 0.013 & $-0.319^{+}$ \\
Onbenefit & $-1.509^{* *}$ & $-1.723^{* *}$ & $-2.192^{* *}$ & $-1.625^{* *}$ & $-1.424^{* *}$ \\
medium distance & $-0.579^{* *}$ & 0.186 & -0.628 & - & - \\
long distance & -0.267 & -0.354 & - & - & - \\
Nat. Unemployment rate & 0.092 & 0.105 & $0.577^{* *}$ & $0.299^{* *}$ & $0.241^{* *}$ \\
Unemployment rate at entry & $0.298^{* *}$ & 0.072 & 0.049 & 0.097 & 0.029 \\
2-3 years & 0.010 & $-0.943^{* *}$ & 0.066 & -0.231 & -0.043 \\
3-4 years & -0.398 & $-0.691^{+}$ & -0.085 & -0.135 & 0.277 \\
$>$ 4 years & 0.436 & $-0.666^{+}$ & -0.202 & 0.417 & $-1.124^{+}$ \\
\hline
\end{tabular}

Notes: SE in parentheses. ${ }^{+}: p<0.05$ and ${ }^{* *}: p<0.01$. 
Table 6 Estimated effect of divorce on return migration hazards.

\begin{tabular}{|c|c|c|c|c|c|}
\hline Constant & $\begin{array}{l}-0.059 \\
(0.097)\end{array}$ & $\begin{array}{l}0.944^{* *} \\
(0.144)\end{array}$ & $\begin{array}{l}\text { LDC } \\
\text { Model } 1 \\
1.875^{* *} \\
(0.296)\end{array}$ & $\begin{array}{l}1.350^{* *} \\
(0.086)\end{array}$ & $\begin{array}{l}1.375^{* *} \\
(0.098)\end{array}$ \\
\hline \multirow{3}{*}{ Constant } & & & Model 2 & & \\
\hline & -0.037 & $0.932^{* *}$ & $1.786^{* *}$ & $1.358^{* *}$ & $1.420^{* *}$ \\
\hline & $(0.100)$ & $(0.164)$ & $(0.314)$ & $(0.095)$ & $(0.106)$ \\
\hline \multirow[t]{2}{*}{$2-3$ years } & -0.165 & 0.067 & -0.047 & -0.187 & -0.114 \\
\hline & $(0.178)$ & $(0.217)$ & $(0.306)$ & $(0.228)$ & $(0.228)$ \\
\hline \multirow[t]{3}{*}{$>3$ years } & -0.042 & -0.006 & 0.446 & 0.131 & -0.258 \\
\hline & $(0.174)$ & $(0.212)$ & $(0.272)$ & $(0.215)$ & $(0.256)$ \\
\hline & \multicolumn{5}{|c|}{ Model 3} \\
\hline \multirow[t]{2}{*}{ Constant } & -0.160 & $0.657^{* *}$ & $1.431^{* *}$ & $1.244^{* *}$ & $1.304^{* *}$ \\
\hline & $(0.157)$ & $(0.193)$ & $(0.346)$ & $(0.140)$ & $(0.140)$ \\
\hline \multirow[t]{2}{*}{$2-3$ years } & -0.152 & 0.075 & -0.037 & -0.176 & -0.050 \\
\hline & $(0.179)$ & $(0.219)$ & $(0.306)$ & $(0.221)$ & $(0.228)$ \\
\hline \multirow[t]{2}{*}{$>3$ years } & -0.012 & 0.003 & 0.417 & 0.104 & -0.194 \\
\hline & $(0.175)$ & $(0.213)$ & $(0.274)$ & $(0.214)$ & $(0.254)$ \\
\hline \multirow[t]{2}{*}{ Male } & 0.012 & 0.291 & 0.274 & $-0.413^{+}$ & 0.148 \\
\hline & $(0.148)$ & $(0.180)$ & $(0.245)$ & $(0.162)$ & $(0.189)$ \\
\hline \multirow[t]{2}{*}{ No income } & 0.160 & 0.052 & 0.222 & $0.435^{+}$ & $1.010^{* *}$ \\
\hline & $(0.138)$ & $(0.219)$ & $(0.319)$ & $(0.173)$ & $(0.202)$ \\
\hline \multirow[t]{2}{*}{ Aged 18-25 } & $0.628^{* *}$ & $0.764^{* *}$ & $0.826^{* *}$ & $0.658^{* *}$ & $0.353^{+}$ \\
\hline & $(0.165)$ & $(0.206)$ & $(0.258)$ & $(0.152)$ & $(0.175)$ \\
\hline EU15 & $\begin{array}{l}-0.089 \\
(0.147)\end{array}$ & - & - & - & - \\
\hline
\end{tabular}

Notes: SE in parentheses. ${ }^{+}: p<0.05$ and $^{* *}: p<0.01$. 
Table 7 Estimated effect of re-marriage on return migration hazards.

\begin{tabular}{|c|c|c|c|c|c|}
\hline Constant & $\begin{array}{c}\text { DC } \\
-1.501^{* *} \\
(0.210)\end{array}$ & $\begin{array}{c}0.457 \\
(0.311)\end{array}$ & $\begin{array}{c}\text { LDC } \\
\text { Model 1 } \\
1.167^{+} \\
(0.513)\end{array}$ & $\begin{array}{l}0.810^{* *} \\
(0.235)\end{array}$ & $\begin{array}{l}1.255^{* *} \\
(0.201)\end{array}$ \\
\hline & & & Model 2 & & \\
\hline Constant & $\begin{array}{c}-1.533^{* *} \\
(0.284)\end{array}$ & $\begin{array}{l}0.669^{+} \\
(0.337)\end{array}$ & $\begin{array}{l}1.320^{+} \\
(0.555)\end{array}$ & $\begin{array}{l}0.645^{+} \\
(0.293)\end{array}$ & $\begin{array}{l}1.144^{* *} \\
(0.244)\end{array}$ \\
\hline $2-3$ years & $\begin{array}{c}0.307 \\
(0.475)\end{array}$ & $\begin{array}{l}-0.741 \\
(1.050)\end{array}$ & $\begin{array}{l}-0.890 \\
(1.156)\end{array}$ & $\begin{array}{c}0.949 \\
(0.495)\end{array}$ & $\begin{array}{c}0.605 \\
(0.453)\end{array}$ \\
\hline$>3$ years & $\begin{array}{l}-0.088 \\
(0.446)\end{array}$ & $\begin{array}{l}-0.992 \\
(1.050)\end{array}$ & $\begin{array}{c}0.665 \\
(1.114)\end{array}$ & $\begin{array}{l}-0.425 \\
(0.949)\end{array}$ & $\begin{array}{l}-0.105 \\
(0.677)\end{array}$ \\
\hline Constant & $\begin{array}{c}-1.607^{* *} \\
(0.433)\end{array}$ & $\begin{array}{c}0.535 \\
(0.438)\end{array}$ & $\begin{array}{c}\text { Model } 3 \\
1.498^{+} \\
(0.689)\end{array}$ & $\begin{array}{l}0.759^{+} \\
(0.312)\end{array}$ & $\begin{array}{l}1.358^{* *} \\
(0.297)\end{array}$ \\
\hline 2-3 years & $\begin{array}{c}0.368 \\
(0.476)\end{array}$ & $\begin{array}{l}-0.714 \\
(1.052)\end{array}$ & $\begin{array}{l}-0.879 \\
(2.600)\end{array}$ & $\begin{array}{c}0.933 \\
(0.498)\end{array}$ & $\begin{array}{c}0.623 \\
(0.452)\end{array}$ \\
\hline$>3$ years & $\begin{array}{c}0.048 \\
(0.449)\end{array}$ & $\begin{array}{l}-0.962 \\
(1.054)\end{array}$ & $\begin{array}{c}0.674 \\
(1.116)\end{array}$ & $\begin{array}{l}-0.459 \\
(0.961)\end{array}$ & $\begin{array}{l}-0.193 \\
(0.690)\end{array}$ \\
\hline Male & $\begin{array}{l}1.252^{* *} \\
(0.430)\end{array}$ & $\begin{array}{c}0.290 \\
(0.589)\end{array}$ & $\begin{array}{l}-0.320 \\
(0.847)\end{array}$ & $\begin{array}{l}-0.182 \\
(0.539)\end{array}$ & $\begin{array}{l}-0.396 \\
(0.401)\end{array}$ \\
\hline EU15 & $\begin{array}{l}-0.363 \\
(0.380)\end{array}$ & & & & \\
\hline
\end{tabular}

Notes: SE in parentheses. ${ }^{+}: p<0.05$ and $^{* *}: p<0.01$. 
Table 8 The impact of the incidence of divorce on return-migration hazards

\begin{tabular}{l|ccccc}
\hline & DC & IDC & LDC & Turkey & Morocco \\
\hline \multirow{3}{*}{ PH-model } & \multirow{5}{c}{ Divorce effect } \\
& $0.214^{* *}$ & $0.714^{* *}$ & $0.614^{* *}$ & $1.454^{* *}$ & $1.517^{* *}$ \\
MPH-model & $(0.055)$ & $(0.082)$ & $(0.099)$ & $(0.073)$ & $(0.082)$ \\
& $0.235^{* *}$ & $0.735^{* *}$ & $0.765^{* *}$ & $1.457^{* *}$ & $1.528^{* *}$ \\
& $(0.059)$ & $(0.090)$ & $(0.128)$ & $(0.074)$ & $(0.084)$ \\
Timing of & -0.059 & $0.944^{* *}$ & $1.875^{* *}$ & $1.350^{* *}$ & $1.375^{* *}$ \\
Events model 1 & $(0.097)$ & $(0.144)$ & $(0.296)$ & $(0.086)$ & $(0.098)$ \\
\hline \multirow{3}{*}{ PH-model } & $-0.863^{* *}$ & 0.063 & -0.165 & $0.782^{* *}$ & $1.198^{* *}$ \\
& $(0.183)$ & $(0.291)$ & $(0.411)$ & $(0.223)$ & $(0.196)$ \\
MPH-model & $-0.878^{* *}$ & 0.077 & 0.109 & $0.780^{* *}$ & $1.201^{* *}$ \\
& $(0.191)$ & $(0.307)$ & $(0.475)$ & $(0.224)$ & $(0.202)$ \\
Timing of & $-1.501^{* *}$ & 0.457 & $1.167^{+}$ & $0.810^{* *}$ & $1.255^{* *}$ \\
Events model 1 & $(0.210)$ & $(0.311)$ & $(0.513)$ & $(0.235)$ & $(0.201)$ \\
\hline
\end{tabular}

${ }^{+} p<0.05$ and ${ }^{* *} p<0.01$ 
Table 9 The effect of changing the choice of the cut-off point between DC, IDC and LDC in model 1

\begin{tabular}{l|ccc|ccc}
\hline & DC & IDC & LDC & DC & IDC & LDC \\
\hline \multirow{3}{*}{ Cut-off 1 $^{\mathrm{a}}$} & \multicolumn{3}{c|}{ Divorce effect } & \multicolumn{3}{c}{ Re-marriage effect } \\
& -0.193 & $0.850^{* *}$ & $1.864^{* *}$ & $-1.587^{* *}$ & 0.228 & 0.891 \\
Cut-off 2 & $(0.120)$ & $(0.087)$ & $(0.581)$ & $(0.222)$ & $(0.236)$ & $(0.810)$ \\
& -0.193 & $0.896^{* *}$ & $1.403^{* *}$ & $-1.587^{* *}$ & 0.078 & $0.808^{* *}$ \\
Cut-off 3 & $(0.120)$ & $(0.128)$ & $(0.174)$ & $(0.222)$ & $(0.411)$ & $(0.298)$ \\
& -0.136 & $0.796^{* *}$ & $1.875^{* *}$ & $-1.638^{* *}$ & 0.429 & $1.167^{+}$ \\
Cut-off 4 & $(0.100)$ & $(0.116)$ & $(0.296)$ & $(0.217)$ & $(0.267)$ & $(0.513)$ \\
& -0.193 & $0.875^{* *}$ & $1.875^{* *}$ & $-1.587^{* *}$ & 0.226 & $1.167^{+}$ \\
Cut-off 5 & $(0.120)$ & $(0.094)$ & $(0.296)$ & $(0.222)$ & $(0.259)$ & $(0.513)$ \\
& -0.193 & $0.900^{* *}$ & $1.746^{* *}$ & $-1.587^{* *}$ & 0.139 & $1.211^{* *}$ \\
& $(0.120)$ & $(0.095)$ & $(0.238)$ & $(0.222)$ & $(0.296)$ & $(0.399)$ \\
Original cut-off & -0.059 & $0.944^{* *}$ & $1.875^{* *}$ & $-1.501^{* *}$ & 0.457 & $1.167^{+}$ \\
& $(0.097)$ & $(0.144)$ & $(0.296)$ & $(0.210)$ & $(0.311)$ & $(0.513)$ \\
\hline
\end{tabular}

${ }^{+} p<0.05$ and ${ }^{* *} p<0.01$

${ }^{\text {a }}$ DC HDI $\geq 0.793$; IDC $0.522 \leq$ HDI $<0.793$; LDC HDI $<0.522$

${ }^{\mathrm{b}}$ DC HDI $\geq 0.793$; IDC $0.698 \leq$ HDI $<0.793 ;$ LDC HDI $<0.698$

${ }^{c}$ DC HDI $\geq 0.75 ;$ IDC $0.6 \leq$ HDI $<0.75 ;$ LDC HDI $<0.6$

d DC HDI $>0.793 ;$ IDC $0.6<$ HDI $<0.793 ;$ LDC HDI $<0.6$

e DC HDI $\geq 0.793$; IDC $0.65 \leq$ HDI $<0.793$; LDC HDI $<0.65$

${ }^{\mathrm{f}}$ DC HDI $\geq 0.7 ;$ IDC $0.6 \leq \mathrm{HDI}<0.7 ;$ LDC HDI $<0.6$ 
Migrant 1
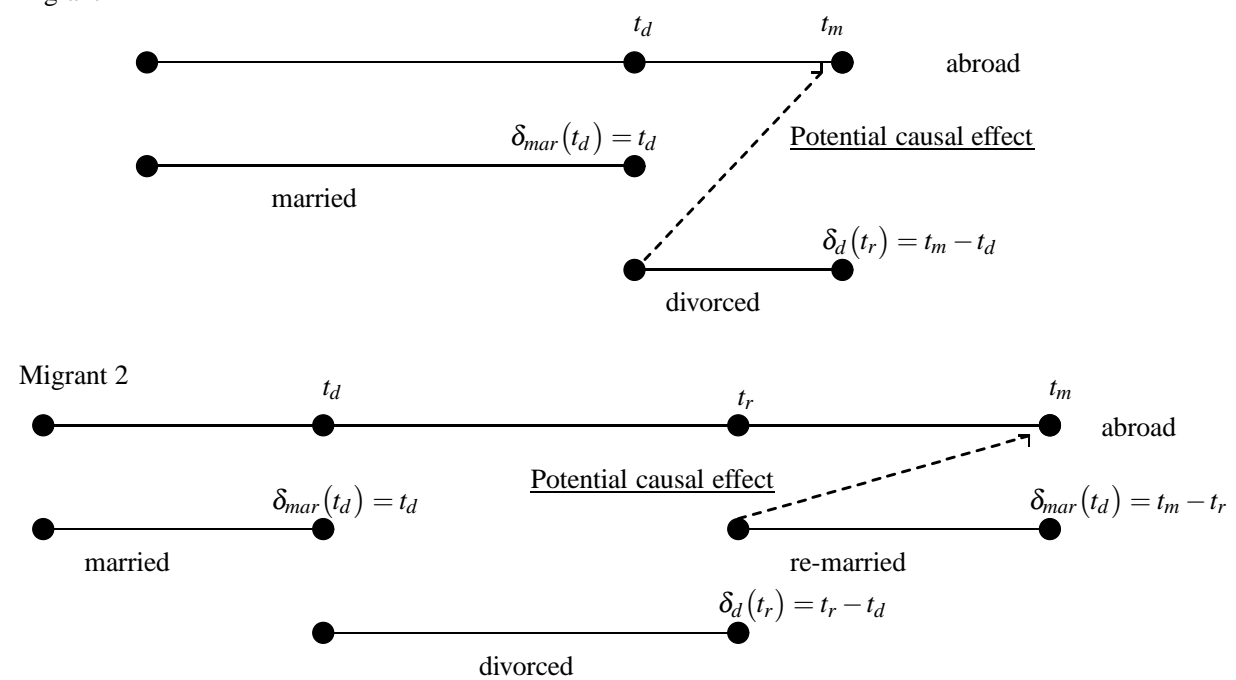

Fig. 1 Migration and marriage dynamics 


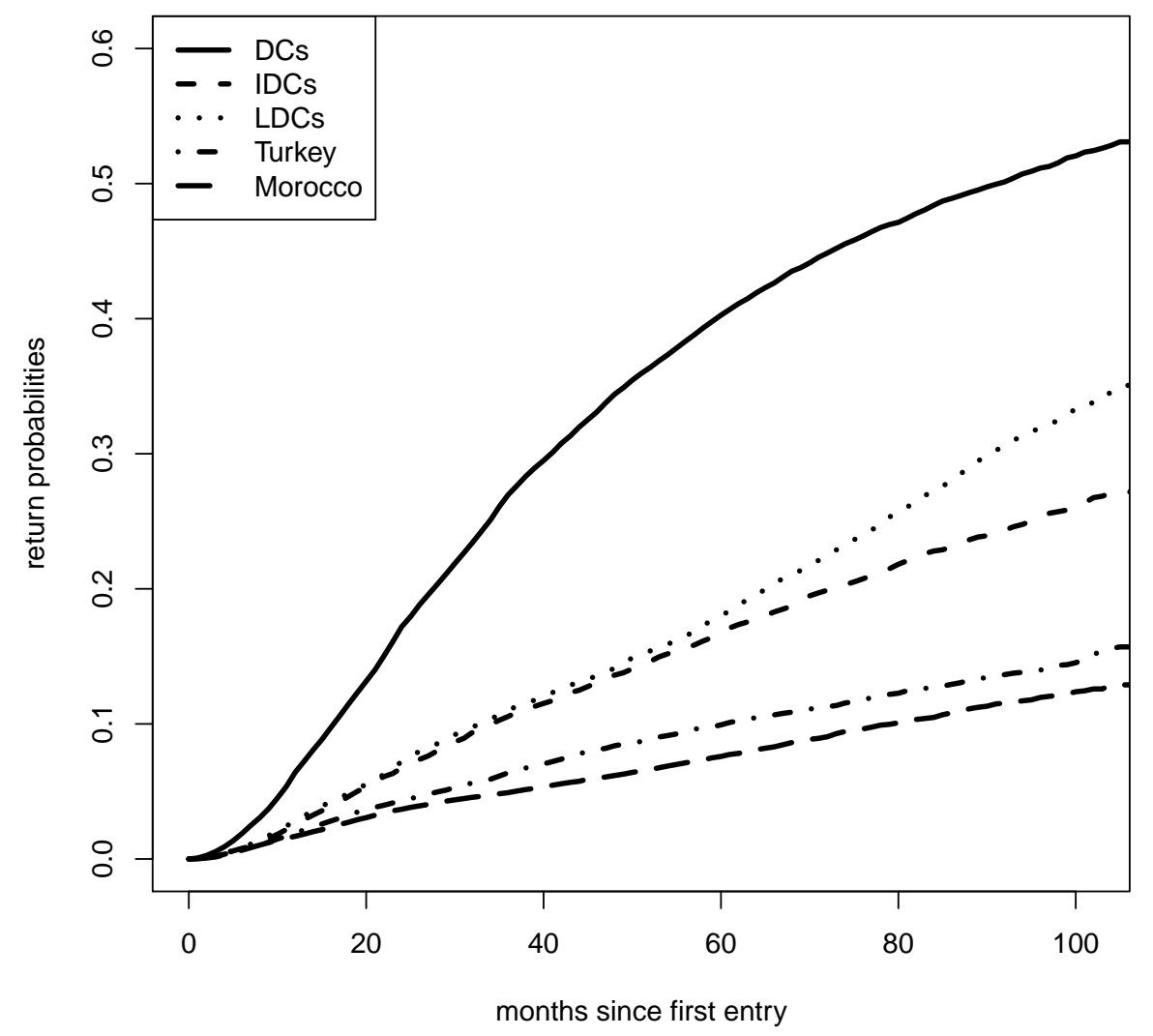

Fig. 2 Kaplan Meier estimates of return probabilities 


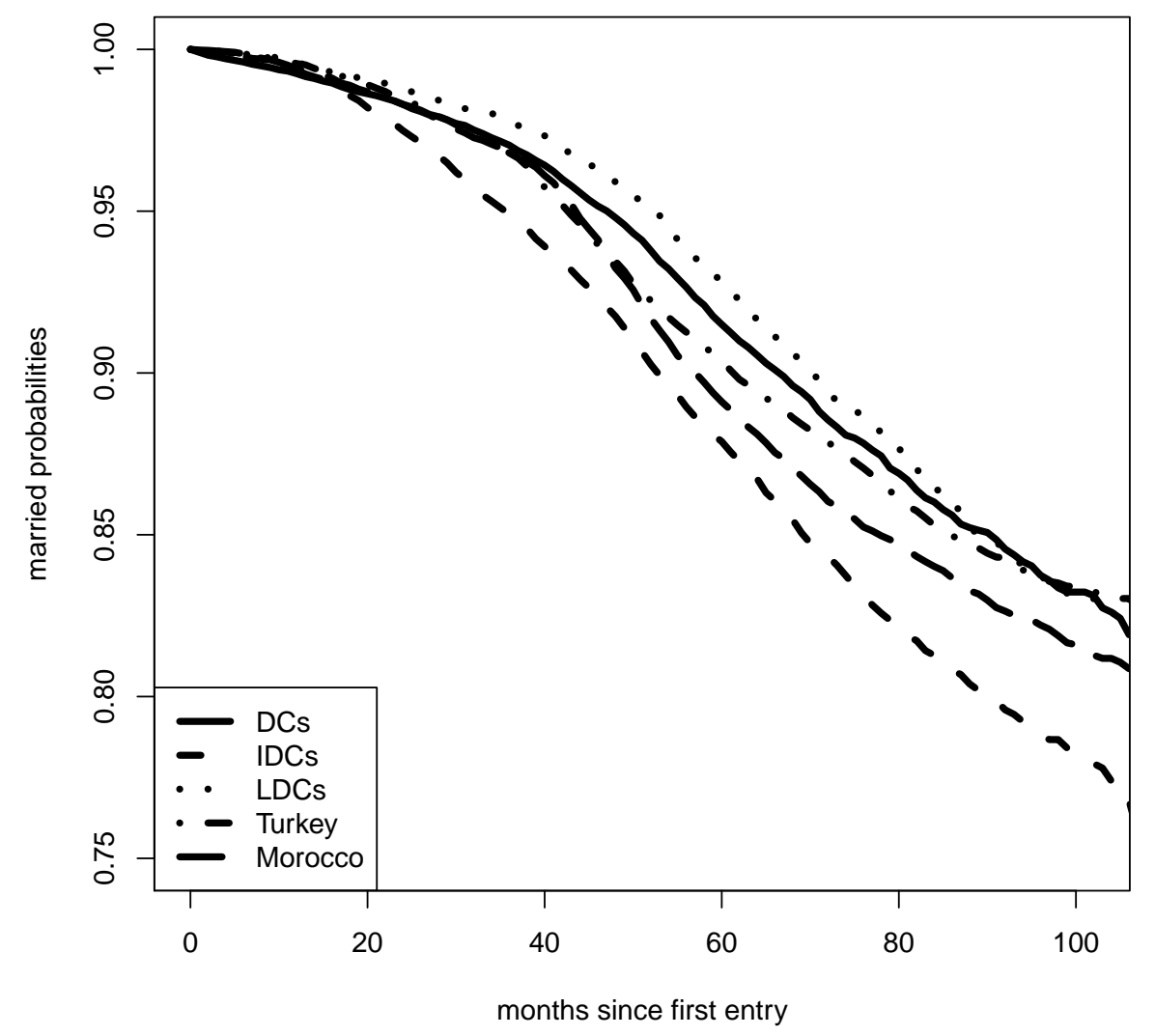

Fig. 3 Kaplan Meier estimates of probability to remain married 


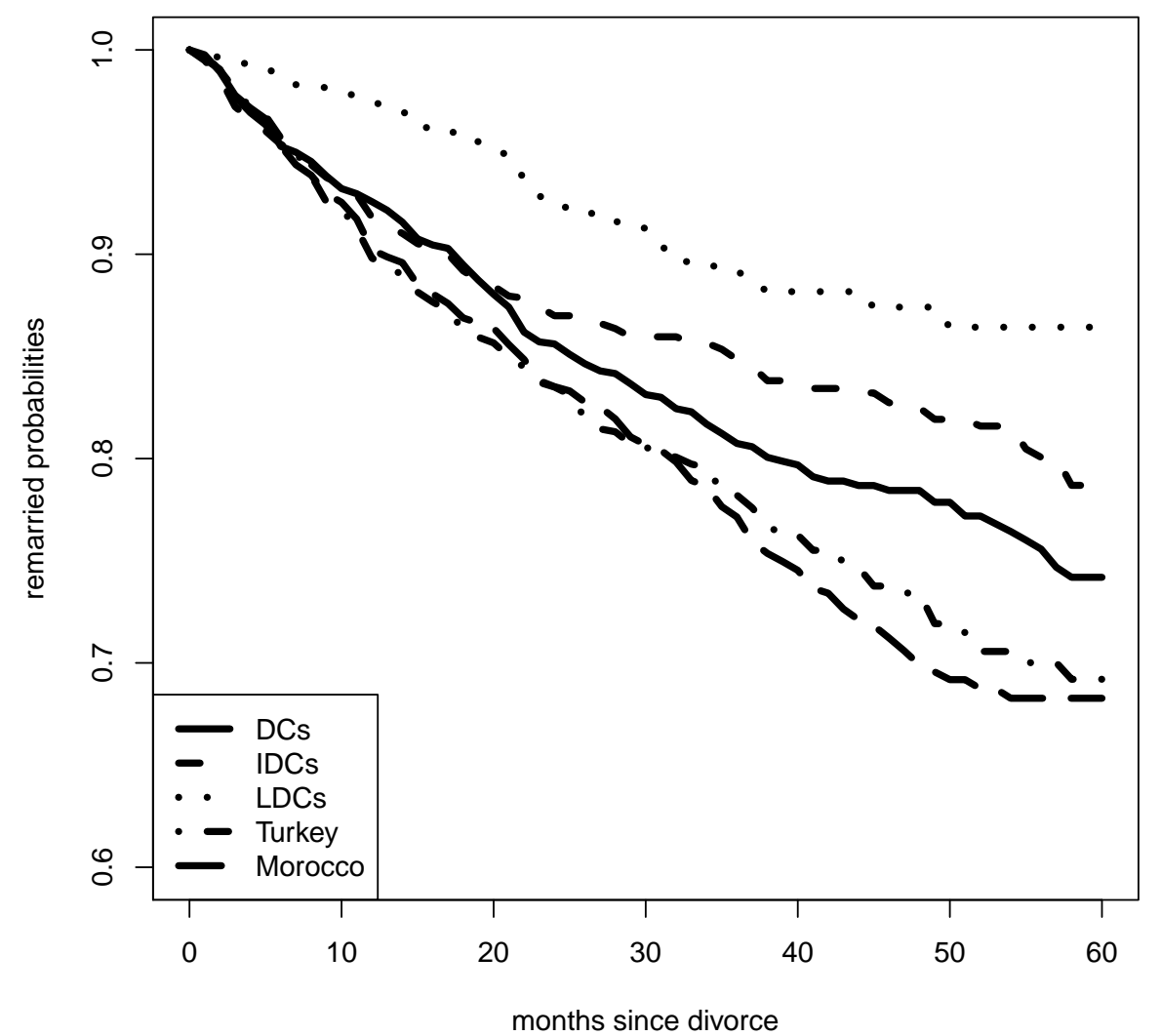

Fig. 4 Kaplan Meier estimates of probability to remain divorced 

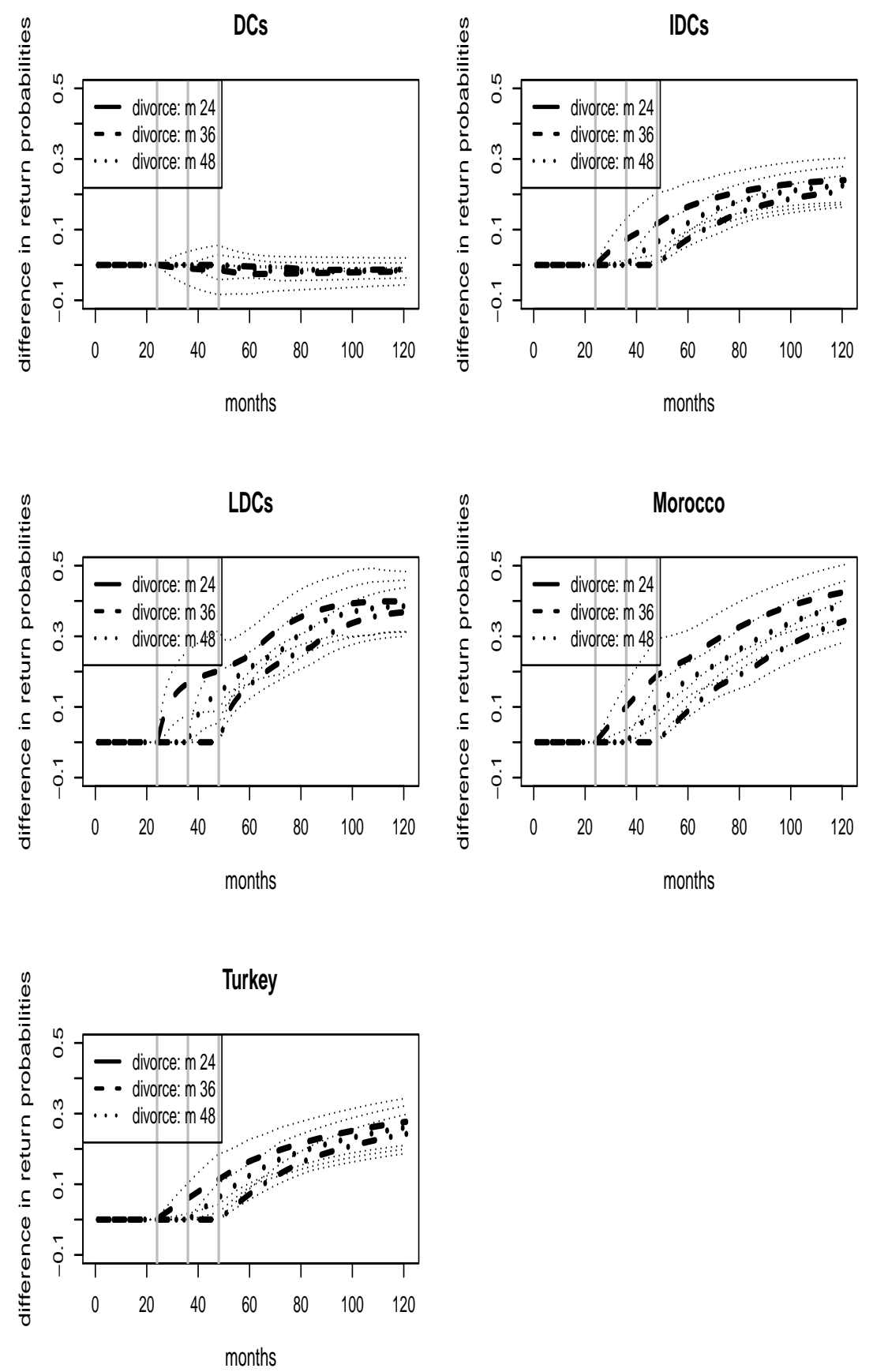

Fig. 5 Effect of timing of divorce: change in return probability 

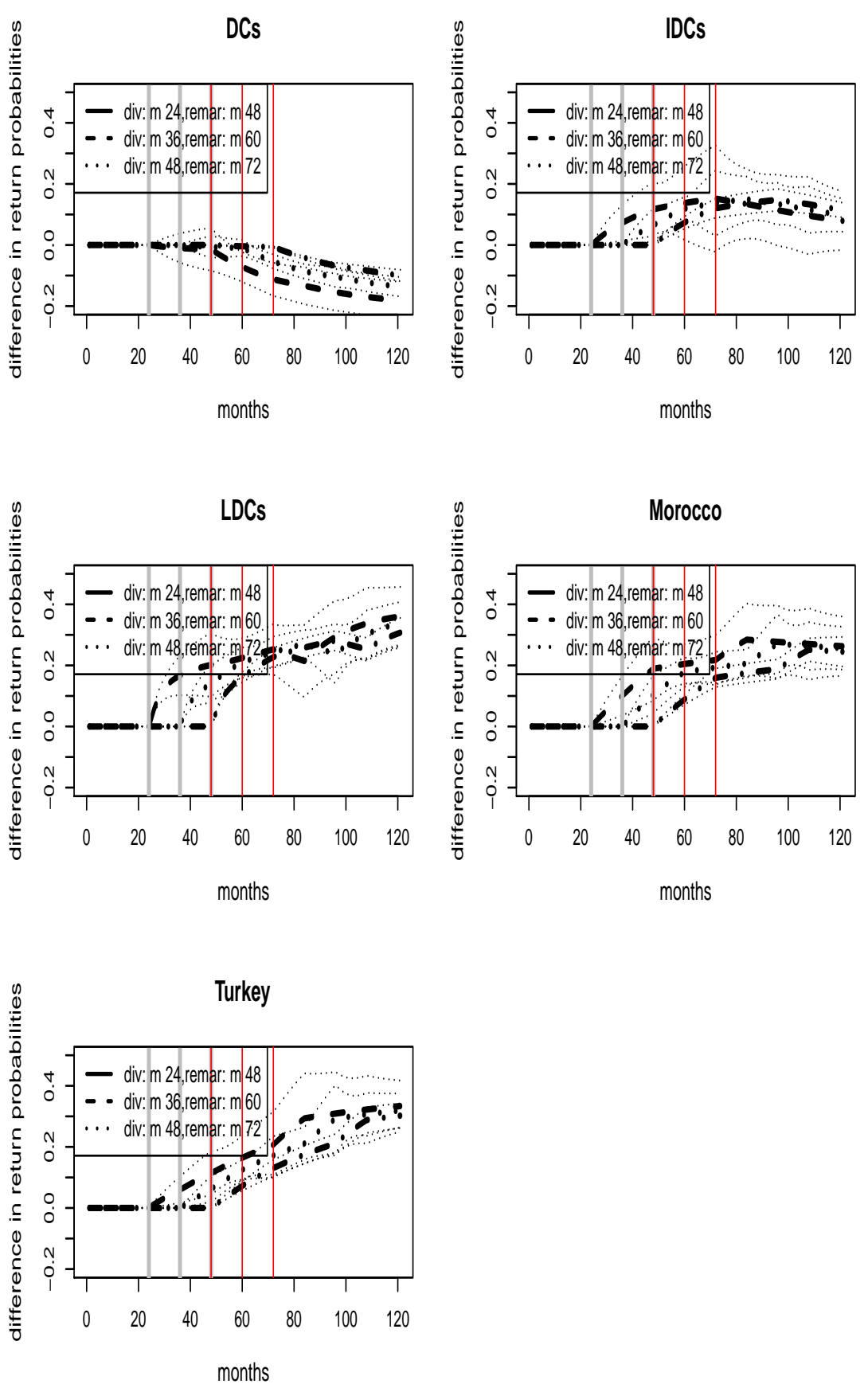

Fig. 6 Effect of timing of divorce and remarriage: change in return probabilities 

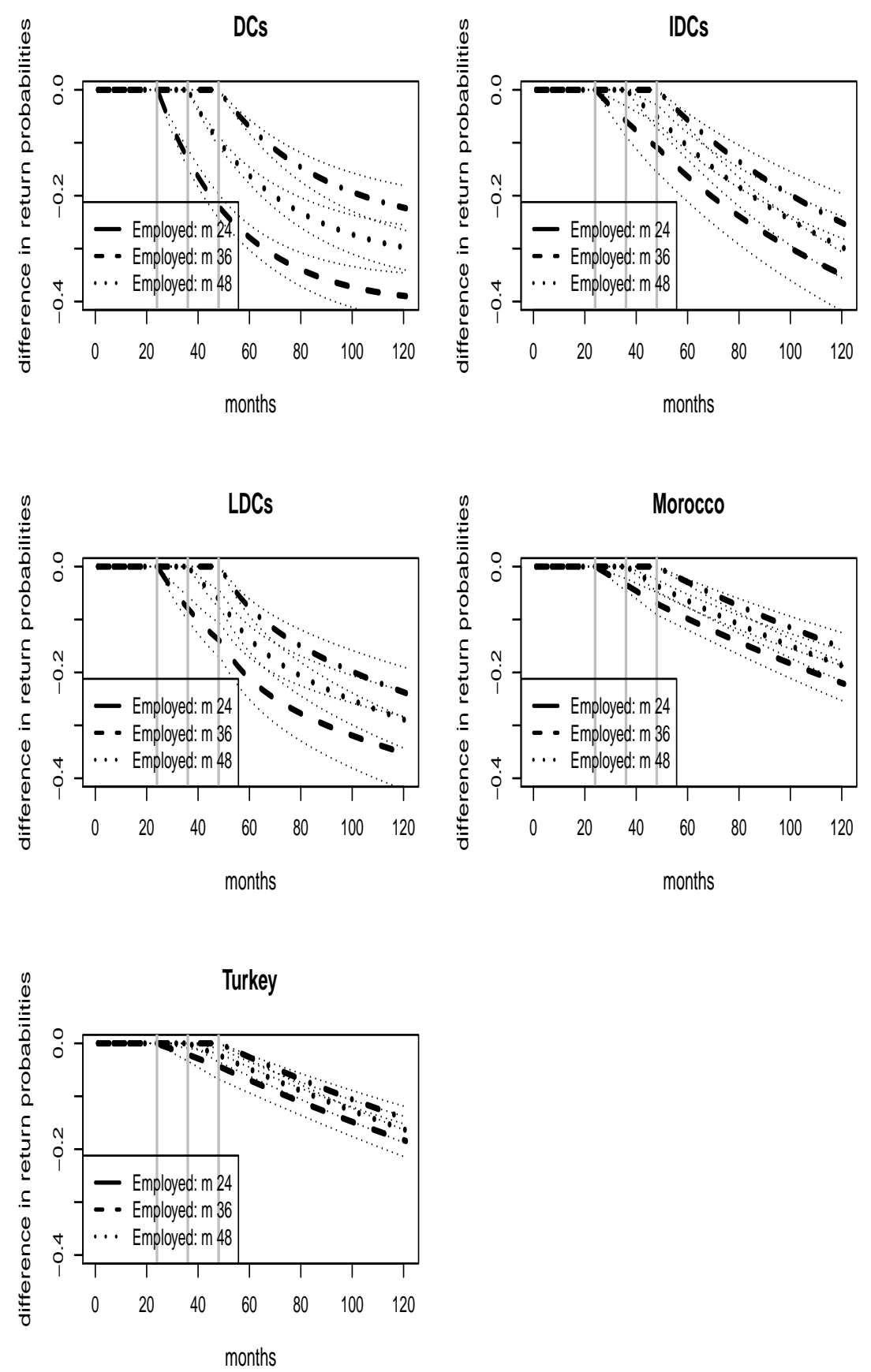

Fig. 7 Effect of timing of employment: change in return probabilities 


\section{A Appendix}

Table 10 to 12 provide information on the migrant groups: the main countries, the HDI and the religion dummy.

Table 10 Main LDC Countries

\begin{tabular}{l|rrrrr}
\hline LDC & $\mathrm{N}$ & $\%$ & HDI & Distance $(\mathrm{km})$ & Religion \\
\hline Iraq & 2197 & 19.0 & 0.573 & 3796 & Muslim \\
Afghanistan & 2152 & 18.6 & 0.398 & 5369 & Muslim \\
India & 1950 & 16.7 & 0.547 & 6368 & \\
Pakistan & 1188 & 10.3 & 0.504 & 5701 & \\
Nigeria & 785 & 6.8 & 0.459 & 5090 & Muslim \\
Ghana & 579 & 5.0 & 0.541 & 5210 & \\
Somalia & 532 & 4.6 & 0.316 & 6717 & Muslim \\
Sudan & 471 & 4.1 & 0.408 & 4758 & Muslim \\
Ethiopia & 317 & 2.7 & 0.363 & 5693 & \\
Bangladesh & 176 & 1.5 & 0.5 & 7649 & \\
Cameroon & 151 & 1.3 & 0.482 & 5412 & \\
Senegal & 141 & 1.2 & 0.459 & 4624 & \\
Gambia & 130 & 1.1 & 0.42 & 4719 & \\
Burundi & 122 & 1.1 & 0.316 & 6591 & \\
\hline Total & 11,570 & & & & \\
\hline
\end{tabular}

Table 11 Main IDC Countries

\begin{tabular}{l|rrrrr}
\hline IDC & $\mathrm{N}$ & $\%$ & HDI & Distance $(\mathrm{km})$ & Religion \\
\hline Surinam & 2942 & 19.7 & 0.68 & 7495 & \\
China & 2393 & 16.0 & 0.687 & 7844 & \\
Indonesia & 2090 & 14.0 & 0.617 & 7055 & Muslim \\
Egypt & 1724 & 11.6 & 0.644 & 3291 & Muslim \\
Thailand & 1014 & 6.8 & 0.682 & 9179 & \\
Philippines & 1014 & 6.8 & 0.644 & 10407 & Christian \\
Southern Africa & 936 & 6.3 & 0.619 & 9648 & \\
\hline Total & 14,917 & & & & \\
\hline
\end{tabular}


Table 12 DC Country Specific Information

\begin{tabular}{|c|c|c|c|c|c|}
\hline $\mathrm{DC}$ & $\mathrm{N}$ & $\%$ & HDI & Distance (km) & Religion \\
\hline Poland & 4158 & 11.98 & 0.813 & 1098 & Christian \\
\hline USA & 3407 & 9.82 & 0.91 & 6206 & \\
\hline Russia & 3275 & 9.44 & 0.755 & 2157 & \\
\hline Japan & 2435 & 7.02 & 0.901 & 9227 & \\
\hline Germany & 2371 & 6.83 & 0.905 & 576 & \\
\hline UK & 2291 & 6.60 & 0.863 & 356 & \\
\hline Yugoslavia & 2229 & 6.42 & 0.728 & 1200 & \\
\hline Iran & 1410 & 4.06 & 0.707 & 4027 & Muslim \\
\hline Brazil & 1084 & 3.12 & 0.718 & 9091 & Christian \\
\hline Romania & 1025 & 2.95 & 0.781 & 1800 & Christian \\
\hline France & 933 & 2.69 & 0.884 & 429 & \\
\hline Belgium & 761 & 2.19 & 0.886 & 171 & \\
\hline Total & 35,269 & & & & \\
\hline
\end{tabular}

Table 13 Mean values of included covariates by migrant-group (at entry).

\begin{tabular}{l|ccccc}
\hline & DC & IDC & LDC & Turkey & Morocco \\
Female & 0.838 & 0.812 & 0.814 & 0.560 & 0.621 \\
\# of children & 0.575 & 0.544 & 0.900 & 0.398 & 0.441 \\
aged 18-20 & 0.031 & 0.049 & 0.058 & 0.227 & 0.158 \\
aged 21-24 & 0.111 & 0.163 & 0.204 & 0.319 & 0.252 \\
aged 25-34 & 0.459 & 0.494 & 0.517 & 0.332 & 0.434 \\
aged 35-50 & 0.335 & 0.260 & 0.197 & 0.108 & 0.144 \\
aged $>$ 50 & 0.064 & 0.034 & 0.024 & 0.014 & 0.013 \\
\hline Low income $(<€ 2000)$ & 0.067 & 0.035 & 0.050 & 0.044 & 0.042 \\
Medium income $(€ 2000-€ 4000)$ & 0.920 & 0.962 & 0.947 & 0.955 & 0.957 \\
High income $(>€ 4000)$ & 0.012 & 0.002 & 0.002 & 0.000 & 0.000 \\
house owned & 0.335 & 0.281 & 0.140 & 0.205 & 0.075 \\
employed & 0.088 & 0.035 & 0.027 & 0.035 & 0.027 \\
\hline EU15 & 0.237 & - & - & - & - \\
Muslim Country & 0.052 & 0.729 & 0.875 & - & - \\
Christian Country & 0.384 & 0.056 & 0.006 & - & - \\
short distance & 0.492 & 0.012 & 0 & - & - \\
medium distance & 0.163 & 0.656 & 0.710 & - & - \\
long distance & 0.345 & 0.332 & 0.290 & - & - \\
N & 35,629 & 14,917 & 11,570 & 20,091 & 18,185 \\
\hline & & & & & \\
\hline & & & & -
\end{tabular}

